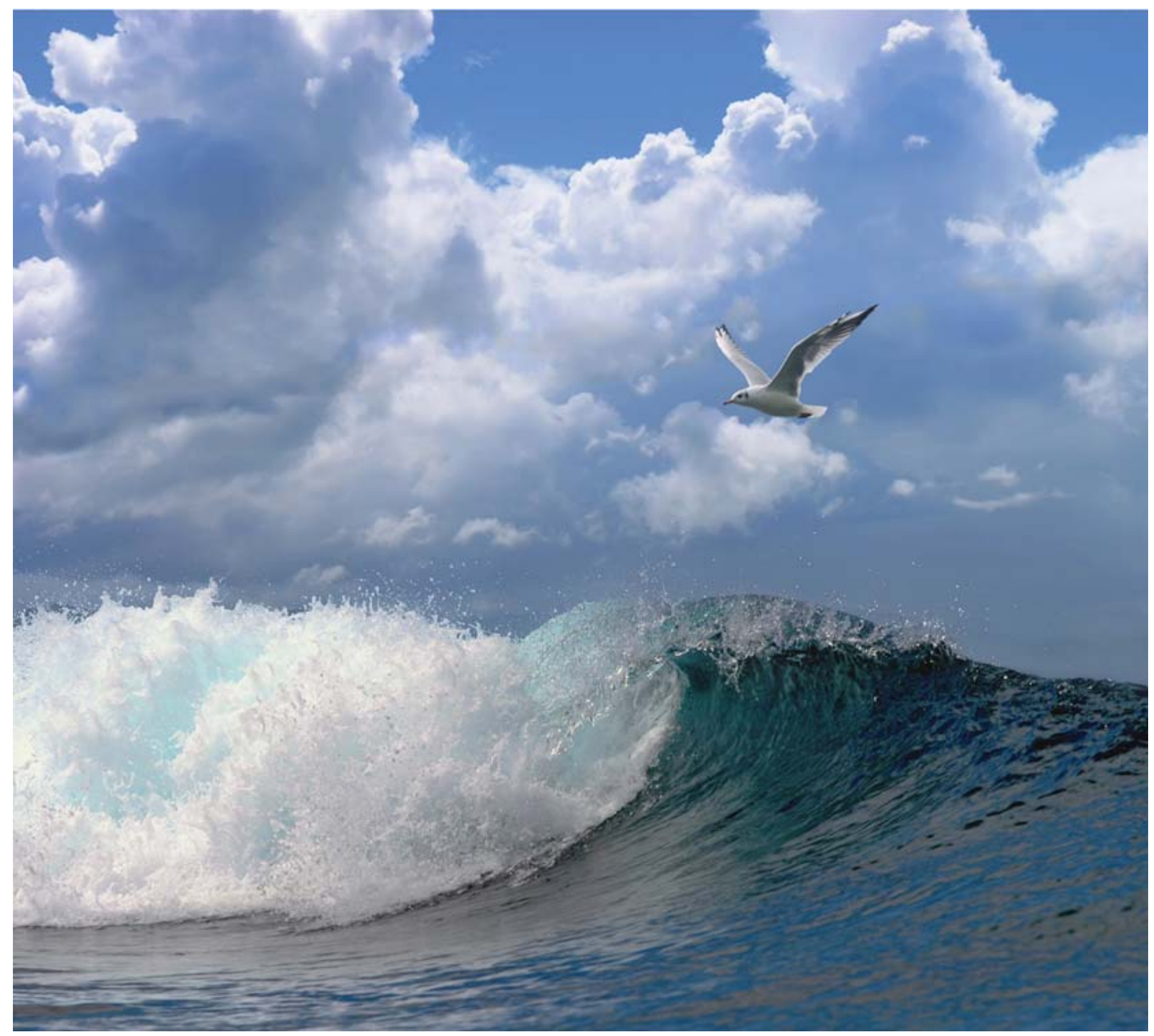

Resultaten van het Rijkswaterstaat J AMP 2016 monitoringsprogramma van schol (Pleuronectes platessa L.) 



\section{Resultaten van het Rijkswaterstaat JAMP 2016 monitoringsprogramma van schol (Pleuronectes platessa L.)}


Tjon-Atsoi, M \& E. van Barneveld, 2017. Resultaten van het Rijswaterstaat J AMP 2016

monitoringsprogramma van schol (Pleuronectes platessa L.) Wageningen Marine Research Wageningen UR (University \& Research centre), Wageningen Marine Research rapport C028/17.

Keywords: plaice monitoring organic contaminants metals

Opdrachtgever: Rijkswaterstaat CIV

T.a.v.: M. Roos

Postbus 17

8200 AA Lelystad

Dit rapport is gratis te downloaden van https://doi.org/10.18174/412006

Wageningen Marine Research verstrekt geen gedrukte exemplaren van rapporten.

Wageningen Marine Research Wageningen UR is ISO 9001:2008 gecertificeerd.

(c) 2017 Wageningen Marine Research Wageningen UR

Wageningen Marine Research, onderdeel van Stichting Wageningen Research KvK nr. 09098104,

IMARES BTW nr. NL 8113.83.696.B16.

Code BIC/SWIFT address: RABONL2U

IBAN code: NL 73 RABO 0373599285
De Directie van Wageningen Marine Research is niet aansprakelijk voor gevolgschade, noch voor schade welke voortvloeit uit toepassingen van de resultaten van werkzaamheden of andere gegevens verkregen van Wageningen Marine Research opdrachtgever vrijwaart Wageningen Marine Research van aanspraken van derden in verband met deze toepassing.

Dit rapport is vervaardigd op verzoek van de opdrachtgever hierboven aangegeven en is zijn eigendom. Niets uit dit rapport mag weergegeven en/of gepubliceerd worden, gefotokopieerd of op enige andere manier gebruikt worden zonder schriftelijke toestemming van de opdrachtgever. 


\section{Inhoud}

$\begin{array}{lr}\text { Samenvatting } & 4\end{array}$

$\begin{array}{llr}1 & \text { Inleiding } & 5\end{array}$

2 Werkzaamheden $\quad 6$

$\begin{array}{llr}3 & \text { Methoden } & 7\end{array}$

$\begin{array}{lll}3.1 & \text { Uitvoering visserij } & 7\end{array}$

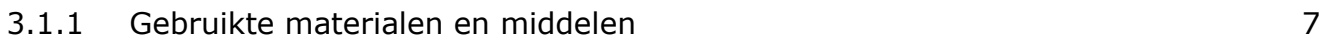

$\begin{array}{ll}3.1 .2 & \text { Activiteiten en locaties }\end{array}$

3.2 Werkwijze voor het verwerken van de vissen tot analysemonsters $\quad 8$

3.2.1 Termen en definities $\quad 8$

$\begin{array}{lll}3.2 .2 & \text { Benodigde materialen } & 8\end{array}$

$\begin{array}{lr}\text { 3.2.3 Activiteiten fileren en monsterverdeling } & 8\end{array}$

$\begin{array}{ll}3.3 \text { Analyses } & 10\end{array}$

3.3.1 PCB's en OCP's 11

3.3.2 Cadmium, zink, koper en lood uitgevoerd door TNO Triskelion 11

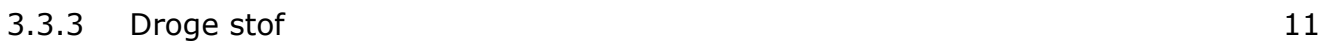

$\begin{array}{lll}3.3 .4 & \text { Vet } & 12\end{array}$

$\begin{array}{lll}3.3 .5 & \text { PBDE'S/HBCD } & 12\end{array}$

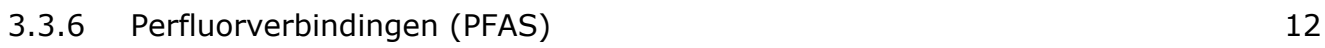

$\begin{array}{lll}3.3 .7 & \text { Kwik } & 12\end{array}$

3.4 Dataopslag en -registratie 13

$\begin{array}{llr}4 & \text { Resultaten } & 14\end{array}$

$\begin{array}{llr}5 & \text { Aanbevelingen } & 17\end{array}$

$\begin{array}{llr}6 & \text { Kwaliteitsborging } & 18\end{array}$

$\begin{array}{lr}\text { Verantwoording } & 20\end{array}$

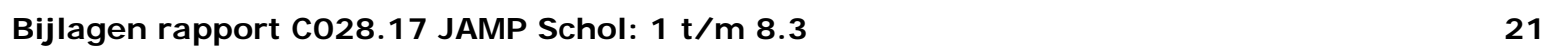




\section{Samenvatting}

In opdracht van Rijkswaterstaat zijn in 2016 door Wageningen Marine Research werkzaamheden uitgevoerd in het kader van het Joint Assessment and Monitoring Program van de OSPARCOM. De werkzaamheden bestonden uit het verzamelen van monsters schol waarin, naast het vaststellen van biologische parameters, milieukritische stoffen zijn geanalyseerd. De verzamelde gegevens en analyse-uitkomsten worden aangeleverd in dit rapport. Deze monitoring van stoffen in biota buiten de 12-mijlszone van de Nederlandse Noordzeekust past ook in het kader van descriptor 8 (Concentraties van vervuilende stoffen) van de KRM.

Het chemisch onderzoek is uitgevoerd op de locaties ten NW van Terschelling, de Bruine Bank en de Doggersbank. De visserij was succesvol. De hoeveelheid monstermateriaal (lever) was, ondanks het verhoogde aantal vissen per monster, laag. In een paar monsters zijn daarom niet alle chemische analyses uitgevoerd. De gemeten gehalten zijn vergelijkbaar met de resultaten van de voorgaande monitoring.

De resultaten van deze opdracht zijn in tabelvorm als bijlagen achter in dit rapport bijgevoegd. 


\section{$1 \quad$ Inleiding}

De in dit rapport beschreven werkzaamheden zijn in 2016 door Wageningen Marine Research uitgevoerd op basis van een opdracht van Rijkswaterstaat in het kader van het Joint Assessment and Monitoring Program van de OSPARCOM. De opdracht is gebaseerd op het RWS werkdocument "Monitoring chemische stoffen in schol, meetplan chemisch meetnet MWTL 2014", werkversie 18 augustus 2014.

De werkzaamheden omvatten het verzamelen van monster-materiaal van schol, lever en filet, voor het uitvoeren van de chemische analyses> Daarnaast worden ook biologische gegevens van schol (karakterisering) bepaald. De schollen werden verzameld tijdens de BTS, een Beam (boomkor) Trawl Survey die jaarlijks door Wageningen Marine Research wordt uitgevoerd in augustus/september t.b.v. het Ministerie van EZ. Op deze manier kunnen kosten worden bespaard op de bemonstering.

Vanuit RWS werd het programma geleid door mevr. A. Houben en vanuit Wageningen Marine Research fungeerde $M$. Kotterman als projectleider.

De veldwerkzaamheden vonden plaats aan boord van de Tridens onder supervisie van Ingeborg de Boois (projectleider BTS). Bij Wageningen Marine Research zijn de organisch chemische analyses en de analyses van kwik, vocht en vet uitgevoerd en de leeftijden bepaald. De analyses van cadmium, zink, koper, lood en vocht in de schollevers zijn uitgevoerd door TNO Triskelion, Utrechtseweg 48, $3704 \mathrm{HE}$ te Zeist. 


\section{Werkzaamheden}

In het kader van de hierboven genoemde opdracht zijn aan Wageningen Marine Research de volgende werkzaamheden opgedragen:

1. Het uitvoeren van de visserij

2. Het bemonsteren van schol

3. Het uitvoeren van biologisch onderzoek (karakteriseren)

4. Het verzamelen van materiaal voor chemische analyses

5. Het uitvoeren van chemische analyses

6. Het rapporteren van de verkregen resultaten. 


\section{Methoden}

\subsection{Uitvoering visserij}

Voor de monstername van de benodigde schollen voor dit project is gebruik gemaakt van het onderzoeksvaartuig de Tridens. De monstername heeft plaatsgevonden tijdens de survey BTS in augustus/september (week 35 en week 37) 2016.

De bemonsterde schollen zijn als proefdieren behandeld. Een goedgekeurd proefplan voor deze opdracht met betrekking tot de Wet op de Dierproeven was aan boord aanwezig.

\subsubsection{Gebruikte materialen en middelen}

- Meetlat met schaalverdeling in $\mathrm{mm}$ (vereiste nauwkeurigheid: op 0 decimalen)

- Weegapparatuur in grammen (vereiste nauwkeurigheid: op 1 decimaal)

- Hamertje t.b.v. diervriendelijk doden

- Droogijs, in totaal $3 \times 20 \mathrm{~kg}$ in 3 polystyreen dozen, aan boord te verdelen over de 6 benodigde polystyreen dozen ( 2 per locatie nodig)

- $\quad$ Thermische handschoenen t.b.v. het hanteren van droogijs

- Veiligheidsbril t.b.v. het hanteren van droogijs

- 6 Polystyreen dozen I x b x h $=55 \times 38 \times 27 \mathrm{~cm}$, waarvan 3 gevuld met droogijs

- Rollen aluminiumfolie

- Groene papiertjes om de schollen te labelen, potlood

- Klembord A4-formaat incl. 4 schrijflijsten (bijlage 1 visserijgegevens)

- $\quad$ Materiaal om de polystyreendozen te labelen (zwart schrijvende Edding stift)

- Proefplan goedgekeurd door de DEC

- Benodigde ontheffingen

- Document "Veilig omgaan met droogijs"

\subsubsection{Activiteiten en locaties}

De 3 locaties, bemonsteringsdata en posities die volgens Projectplan RWS zijn bemonsterd zijn weergegeven in tabel 1.

Tabel 1. Te bemonsteren locaties en posities

\begin{tabular}{|l|c|c|c|c|}
\hline Gebied & $\begin{array}{c}\text { Locatiecode conform } \\
\text { DONAR en ICES }\end{array}$ & Datum & Posities & $\begin{array}{c}\text { Coordinaten } \\
\text { conform DONAR }\end{array}$ \\
\hline West van IJmuiden $(80 \mathrm{~km})$ & IJMWT80 & $05-09-16$ & $\begin{array}{l}03^{\circ} 19.2 \mathrm{OL} \\
52^{\circ} 24.5 \mathrm{NB}\end{array}$ & $\begin{array}{l}\text { X } 31920000 \\
\text { Y } 52245000\end{array}$ \\
\hline Locatie NW-Terschelling (40km) & TERSLNWT40 & $22-08-16$ & $\begin{array}{l}04^{\circ} 29.556 \mathrm{OL} \\
53^{\circ} 36.611 \mathrm{NB}\end{array}$ & $\begin{array}{l}\text { X } 42955600 \\
\text { Y } 53366110\end{array}$ \\
\hline Locatie Doggersbank & DOGGBK & $07-09-16$ & $\begin{array}{l}03^{\circ} 03.90 \mathrm{OL} \\
55^{\circ} 13.98 \mathrm{NB}\end{array}$ & $\begin{array}{l}\text { X } 30390000 \\
\text { Y } 55139800\end{array}$ \\
\hline
\end{tabular}

De vangsten zijn vanuit het net in de last gestort. De visserijgegevens zijn weergegeven in bijlage 1. Op iedere locatie zijn 103 uitwendig gezonde vrouwelijke schollen in de lengteklasse $15-30 \mathrm{~cm}$ bemonsterd gedurende het aantal trekken dat daarvoor benodigd is. De trekken duurden niet langer dan een uur om de schollen zo min mogelijk bloot te stellen aan stress en overige schade. Om te beoordelen of het vrouwelijke schollen betreft, zijn deze tegen het licht gehouden en visueel beoordeeld of zij kuit bevatten. Na deze grove selectie zijn de lengtes in $\mathrm{mm}$ (op 0 decimalen nauwkeurig) en de gewichten in g (op 1 decimaal nauwkeurig) gemeten van de 103 individuele schollen per locatie en op een schrijflijst genoteerd. Hierbij is elke vis gelabeld met een groen label 
waarop met potlood het visnummer is geschreven (het visnummer correspondeert met de gemeten lengte en het gewicht van de betreffende vis op de schrijflijst).

De schollen zijn vervolgens, volgens een door de DEC goedgekeurd proefplan, diervriendelijk gedood door de hersens in te slaan met een hamertje, rekening houdend met het feit dat de levers, filets en otolieten in een later stadium op het lab van Wageningen Marine Research zonder beschadigingen uitgeprepareerd moeten kunnen worden.

De schollen zijn individueel (voorzien van een groen label met visnummer) in aluminiumfolie verpakt om verkleven te voorkomen en per locatie in polystyreen dozen snel op droogijs ingevroren en in een vriezer aan boord bewaard. De dozen zijn gelabeld met de locatienaam en de daadwerkelijke vangstpositie is genoteerd op de betreffende schrijflijst.

$\mathrm{Na}$ afloop van de BTS survey zijn de schollen z.s.m. overgebracht naar het laboratorium van Wageningen Marine Research in IJmuiden, waar zij in de vriezer zijn opgeslagen tot aan verdere verwerking tot analysemonsters.

\subsection{Werkwijze voor het verwerken van de vissen tot analysemonsters}

De vissen zijn na ontdooien verwerkt tot analysemonsters op het lab van Wageningen Marine Research te IJmuiden.

\subsubsection{Termen en definities}

- SPE: spoorelementen

- OMV: organische microverontreinigingen

- ISW: intern standaard werkvoorschrift, hetgeen uitvoerig de procedure beschrijft over de uitvoering van bijvoorbeeld de analyse van een bepaalde stofgroep, inclusief de kwaliteitsborging en de kwaliteitsparameters

\subsubsection{Benodigde materialen}

- Snijplank

- Fileermes

- Mes voor leverdissectie (geen fileermes, maar kleiner)

- Weegapparatuur in grammen (vereiste nauwkeurigheid: op 1 decimaal)

- Crushing tubes 50 ml, Firma IKA behorend bij de Ultra Turrax Tube disperser, homogenisator

- $\quad$ Retsch GM200 Grinding container, homogenisator

- 5 monsterpotjes plastic (SPE filets) per locatie voor de mengmonsters, geëtiketteerd met LIMSnummers

- 10 monsterpotjes glas (SPE levers/OMV levers) per locatie voor de mengmonsters, geëtiketteerd met LIMS-nummers

- 3 schrijflijsten, 1 per locatie

- 50 Otolietzakjes per locatie, elastiekjes

\subsubsection{Activiteiten fileren en monsterverdeling}

De volgende algemene aandachtspunten zijn bij het fileren in acht genomen:

- Er wordt gewerkt met een schone snijplank en fileermes, regelmatig afgespoeld met leidingwater.

- Indien een vis na opensnijden ziek blijkt te zijn wordt deze niet gebruikt voor de samenstelling van de chemiemonsters (van de 103 vissen per locatie zijn er steeds 3 reserve)

- Van de eerste 50 vissen worden zowel de levers en de filets steeds van 10 vissen gepoold, zodat 5 mengmonsters levers en 5 mengmonsters filets voor SPE worden verkregen.

- $\quad$ Van de overige 50 vissen worden alleen de levers steeds van 10 vissen gepoold, zodat 5 mengmonsters levers voor OMV worden verkregen.

- Daarnaast worden van alle 100 individuele vissen de otolieten verzameld voor leeftijdsbepaling op een later tijdstip. 
De ontdooide 103 schollen van 1 locatie zijn op oplopend visnummer gesorteerd. Vervolgens zijn de otolieten uit visnummer 1 verwijderd en in een gecodeerd otolietenzakje tot aan de bepaling van de leeftijd bewaard. Daarna is schol nummer 1 gefileerd door eerst de lever in zijn geheel uit te prepareren en deze te wegen. Het levergewicht in g (op 1 decimaal nauwkeurig) is op de schrijflijst bij het juiste visnummer genoteerd en de lever is in een gecodeerd glazen SPE leverpotje voor het eerste mengmonster voor de analyse van metalen bewaard. Daarna is de vis verder gefileerd door de filet van de bruine kant te verzamelen in een gecodeerd plastic SPE filetpotje voor het eerste mengmonster voor de analyse van kwik. Deze handelingen zijn herhaald totdat de eerste 10 vissen zijn verwerkt. Daarna is dezelfde werkwijze toegepast op de schollen $11 \mathrm{t} / \mathrm{m} 50$ (steeds otolieten per individuele vis verzamelen en levers en filets per 10 vissen poolen). Van de schollen $51 \mathrm{t} / \mathrm{m} 100$ zijn de otolieten van de individuele vissen verzameld in gecodeerde otolietenzakjes en alleen de levers uitgeprepareerd en individueel gewogen en per 10 levers verzameld in een glazen OMV leverpotje voor een mengmonster voor de analyse van organische microcontaminanten. Van de schollen $51 \mathrm{t} / \mathrm{m} 100$ worden dus geen filets verzameld. Zie tabel 2 voor de samenstelling van de mengmonsters van de vissen en welke analyses erin gedaan moeten worden. Aldus worden per locatie 15 mengmonsters voor chemische analyses verkregen.

Tabel 2. Samenstelling van de mengmonsters en gevraagde analyses.

\begin{tabular}{|c|c|c|c|c|c|c|c|}
\hline \multicolumn{8}{|c|}{ Locatie West van IJmuiden (80 km): IJMWT80 } \\
\hline \multicolumn{8}{|c|}{ Analyse nummers mengmonsters spoorelementen } \\
\hline & 1 & 2 & 3 & 4 & 5 & Opslag & \\
\hline Heel & $2016 / 2073$ & $2016 / 2074$ & $2016 / 2075$ & $2016 / 2076$ & $2016 / 2077$ & aluminium folie & lengte, gewichten individueel en mengmonsters, leeftijd individueel \\
\hline Filet & $2016 / 2083$ & $2016 / 2084$ & $2016 / 2085$ & $2016 / 2086$ & $2016 / 2087$ & plastic potten SPE & $\mathrm{Cd}, \mathrm{Cu}, \mathrm{Pb}, \mathrm{Zn}$, droge stof, vet $\mathrm{B} \& \mathrm{D}$ in mengmonsters \\
\hline Lever & $2016 / 2088$ & $2016 / 2089$ & $2016 / 2090$ & $2016 / 2091$ & $2016 / 2092$ & plastic potten SPE & $\mathrm{Hg}$, droge stof in mengmonsters \\
\hline \multicolumn{8}{|c|}{ Analyse nummers mengmonsters organische contaminanten } \\
\hline & 6 & 7 & 8 & 9 & 10 & Opslag & \\
\hline Heel & $2016 / 2078$ & $2016 / 2079$ & $2016 / 2080$ & $2016 / 2081$ & $2016 / 2082$ & aluminium folie & lengte, gewichten individueel en mengmonsters, leeftijd individueel \\
\hline Lever & $2016 / 2093$ & $2016 / 2094$ & $2016 / 2095$ & $2016 / 2096$ & $2016 / 2097$ & glazen potten OMV & PCB's, OCP's, PBDE's, droge stof, vet in mengmonsters \\
\hline & & & & & & & \\
\hline \multicolumn{8}{|c|}{ Locatie NW-Terschelling (40km): TERSLNWT40 } \\
\hline \multicolumn{8}{|c|}{ Analyse nummers mengmonsters spoorelementen } \\
\hline & 1 & 2 & 3 & 4 & 5 & Opslag & \\
\hline Heel & $2016 / 2098$ & $2016 / 2099$ & $2016 / 2100$ & 2016/2101 & $2016 / 2102$ & aluminium folie & lengte, gewichten individueel en mengmonsters, leeftijd individueel \\
\hline \multicolumn{8}{|c|}{ Analyse nummers mengmonsters organische contaminanten } \\
\hline & 6 & 7 & 8 & 9 & 10 & Opslag & \\
\hline Heel & $2016 / 2103$ & $2016 / 2104$ & $2016 / 2105$ & $2016 / 2106$ & $2016 / 2107$ & aluminium folie & lengte, gewichten individueel en mengmonsters, leeftijd individueel \\
\hline Lever & $2016 / 2118$ & $2016 / 2119$ & $2016 / 2120$ & $2016 / 2121$ & $2016 / 2122$ & glazen potten OMV & PCB's, OCP's, PBDE's, droge stof, vet in mengmonsters \\
\hline & & & & & & & \\
\hline & & & & & & & \\
\hline \multicolumn{8}{|c|}{ Locatie Doggersbank: DOGGBK } \\
\hline \multicolumn{8}{|c|}{ Analyse nummers mengmonsters spoorelementen } \\
\hline & 1 & 2 & 3 & 4 & 5 & Opslag & \\
\hline Heel & $2016 / 2123$ & $2016 / 2124$ & $2016 / 2125$ & $2016 / 2126$ & $2016 / 2127$ & aluminium folie & lengte, gewichten individueel en mengmonsters, leeftijd individueel \\
\hline Filet & $2016 / 2133$ & $2016 / 2134$ & $2016 / 2135$ & $2016 / 2136$ & $2016 / 2137$ & plastic potten SPE & $\mathrm{Cd}, \mathrm{Cu}, \mathrm{Pb}, \mathrm{Zn}$, droge stof, vet $\mathrm{B} \& \mathrm{D}$ in mengmonsters \\
\hline Lever & $2016 / 2138$ & $2016 / 2139$ & $2016 / 2140$ & $2016 / 2141$ & $2016 / 2142$ & plastic potten SPE & $\mathrm{Hg}$, droge stof in mengmonsters \\
\hline \multicolumn{8}{|c|}{ Analyse nummers mengmonsters organische contaminanten } \\
\hline & 6 & 7 & 8 & 9 & 10 & Opslag & \\
\hline Heel & $2016 / 2128$ & $2016 / 2129$ & $2016 / 2130$ & 2016/2131 & $2016 / 2132$ & aluminium folie & lengte, gewichten individueel en mengmonsters, leeftijd individueel \\
\hline Lever & $2016 / 2143$ & $2016 / 2144$ & $2016 / 2145$ & $2016 / 2146$ & $2016 / 2147$ & glazen potten OMV & PCB's, OCP's, PBDE's, droge stof, vet in mengmonsters \\
\hline
\end{tabular}

Na de samenstelling van de (meng)monsters zijn deze gehomogeniseerd. Voor het homogeniseren van de levermonsters zijn Crushing tubes van de firma IKA behorend bij de Ultra Turrax Tube disperser gebruikt en voor het homogeniseren van de filets is de Retsch GM200 Grinding container gebruikt. Na homogeniseren zijn de gevraagde analyses uitgevoerd. De analyses van de metalen, behalve kwik, zijn uitbesteed aan TNO Triskelion.

Zie ook paragraaf 3.3 Analyses. 


\subsection{Analyses}

De volgende chemische componenten zijn volgens projectplan geanalyseerd en gerapporteerd:

\begin{tabular}{|c|c|c|c|}
\hline Component & Rapport & Donar-code & CAS-nummer \\
\hline Percentage droge stof & Droge stof \% & $\% \mathrm{DS}$ & n.v.t. \\
\hline Vet: totaal B\&D & Vet B\&D & VET & n.v.t. \\
\hline Kwik & Kwik & $\mathrm{Hg}$ & $7439-97-6$ \\
\hline Cadmium & Cadmium & $\mathrm{Cd}$ & $7440-43-9$ \\
\hline Koper & Koper & $\mathrm{Cu}$ & $7440-50-8$ \\
\hline Lood & Lood & $\mathrm{Pb}$ & $7439-92-1$ \\
\hline Zink & Zink & $\mathrm{Zn}$ & $7440-66-6$ \\
\hline 2,2,4'-trichloorbifenyl & CB-28 & PCB28 & $7012-37-5$ \\
\hline 2, $4^{\prime}, 5$-trichloorbifenyl & CB-31 & PCB31 & $16606-02-3$ \\
\hline $2,2^{\prime}, 4,4^{\prime}$-tetrachoorbifenyl & CB-47 & PCB47 & $2437-79-8$ \\
\hline $2,2^{\prime}, 4,5^{\prime}$-tetrachoorbifenyl & CB-49 & PCB49 & $41464-40-8$ \\
\hline $2,2^{\prime}, 5,5^{\prime}$-tetrachoorbifenyl & CB-52 & PCB52 & $35693-99-3$ \\
\hline $2,3,3^{\prime}, 4^{\prime}$-tetrachoorbifenyl & CB-56 & PCB56 & $41464-43-1$ \\
\hline 2,3,4,4'-tetrachloorbifenyl & CB-66 & PCB66 & $32598-10-0$ \\
\hline $2,2^{\prime}, 3,4,4^{\prime}$-pentachloorbifenyl & CB-85 & PCB85 & $65510-45-4$ \\
\hline $2,2^{\prime}, 3,4,5^{\prime}$-pentachloorbifenyl & CB-87 & PCB87 & $38380-02-8$ \\
\hline $2,2^{\prime}, 3,4^{\prime}, 5^{\prime}$-pentachloorbifenyl & CB-97 & PCB97 & $41464-51-1$ \\
\hline $2,2^{\prime}, 4,5,5^{\prime}$-pentachloorbifenyl & CB-101 & PCB101 & $37680-73-2$ \\
\hline $2,2^{\prime}, 3,4,5,5^{\prime}$-hexachloorbifenyl & CB-105 & PCB105 & $32598-14-4$ \\
\hline $2,3,3^{\prime}, 4^{\prime}, 6$-pentachloorbifenyl & CB-110 & PCB110 & $38380-03-9$ \\
\hline $2,3^{\prime}, 4,4^{\prime}, 5$-pentachloorbifenyl & CB-118 & PCB118 & $31508-00-6$ \\
\hline $2,2^{\prime}, 3,3^{\prime}, 4,4^{\prime}$-hexachloorbifenyl & CB-128 & PCB128 & $38380-07-3$ \\
\hline $2,2^{\prime}, 3,4,4^{\prime}, 5$-hexachloorbifenyl & CB-137 & PCB137 & $35694-06-5$ \\
\hline $2,2^{\prime}, 3,4,4^{\prime}, 5^{\prime}$-hexachloorbifenyl & CB-138 & PCB138 & $35065-28-2$ \\
\hline $2,2^{\prime}, 3,4,5,5^{\prime}$-hexachloorbifenyl & CB-141 & PCB141 & $52712-04-6$ \\
\hline $2,2^{\prime}, 3,4^{\prime}, 5^{\prime}, 6$-hexachloorbifenyl & CB-149 & PCB149 & $38380-04-0$ \\
\hline $2,2^{\prime}, 3,5,5^{\prime}, 6$-hexachloorbifenyl & CB-151 & PCB151 & $52663-63-5$ \\
\hline $2,2^{\prime}, 4,4^{\prime}, 5,5^{\prime}$-hexachloorbifenyl & CB-153 & PCB153 & $35065-27-1$ \\
\hline $2,3,3^{\prime}, 4,4^{\prime}, 5$-hexachloorbifenyl & CB-156 & PCB156 & $38380-08-4$ \\
\hline $2,2^{\prime}, 3,3^{\prime}, 4,4^{\prime}, 5$-heptachloorbifenyl & CB-170 & PCB170 & $35065-30-6$ \\
\hline $2,2^{\prime}, 3,4,4^{\prime}, 5,5^{\prime}$-heptachloorbifenyl & CB-180 & PCB180 & $35065-29-3$ \\
\hline $2,2^{\prime}, 3,4^{\prime}, 5,5^{\prime}, 6$-heptachlorrbifenyl & CB-187 & PCB187 & $52663-68-0$ \\
\hline $2,2^{\prime}, 3,3^{\prime}, 4,4^{\prime}, 5,5^{\prime}$-octachloorbifenyl & CB-194 & PCB194 & $35694-08-7$ \\
\hline $2,2^{\prime}, 3,3^{\prime}, 5,5^{\prime}, 6,6^{\prime}$-octachloorbifenyl & CB-202 & PCB202 & $2136-99-4$ \\
\hline $2,2^{\prime}, 3,3^{\prime}, 4,4^{\prime}, 5,5^{\prime}, 6$-nonachloorbifenyl & CB-206 & PCB206 & $40186-72-9$ \\
\hline Hexachloorbenzeen & $\mathrm{HCB}$ & $\mathrm{HCB}$ & $118-74-1$ \\
\hline Hexachloorbutadieen & HCBD & HxClbtDen & $87-68-3$ \\
\hline Heptachloor & Heptachloor & $\mathrm{HpCl}$ & $76-44-8$ \\
\hline 2,4,4'-tribroomdifenylether & BDE28 & PBDE28 & $41318-75-6$ \\
\hline $2,2^{\prime}, 4,4^{\prime}$-tribroomdifenylether & BDE47 & PBDE47 & $5436-43-1$ \\
\hline $2,3^{\prime}, 4,4^{\prime}$-tetrabroomdifenylether & BDE66 & PBDE66 & $189084-61-5$ \\
\hline $2,2^{\prime}, 3,4,4^{\prime}$-pentabroomdifenylether & BDE85 & PBDE85 & $182346-21-0$ \\
\hline $2,2^{\prime} 4,4^{\prime}$-tetrabroomdifenylether & BDE99 & PBDE99 & $60348-60-9$ \\
\hline $2,2^{\prime}, 4,5^{\prime}$-tetrabroomdifenylether & BDE100 & PBDE100 & $189084-64-8$ \\
\hline 2,4,4',6-tetrabroomdifenylether & BDE153 & PBDE153 & $68631-49-2$ \\
\hline Som PBB153 en PBDE154 & BDE154+BB153 & SPBB153DE154 & n.v.t. \\
\hline $2,2^{\prime}, 4,4^{\prime}, 5,5^{\prime}$-hexabroombifenyl & BB153 & PBB153 & $59080-40-9$ \\
\hline $2,2^{\prime}, 4,4^{\prime}, 5,6^{\prime}$-hexabroomdifenylether & BDE154 & PBDE154 & $207122-15-4$ \\
\hline $2,2^{\prime}, 3,4,4^{\prime}, 5^{\prime}, 6$-heptabroomdifenylether & BDE183 & PBDE183 & 207122-16-5 \\
\hline Hexabromocyclododecanen & $\mathrm{HBCD}$ & $\mathrm{HBCD}$ & $25637-99-4$ \\
\hline
\end{tabular}




\begin{tabular}{|l|l|l|l|}
\hline Component & Rapport & Donar-code & CAS-nummer \\
\hline Perfluor-n-butaanzuur & PFBA & PFBA & $375-22-4$ \\
\hline Perfluorbutaansulfonaat & PFBS & PFBS & $375-73-5$ \\
\hline Perfluordecaanzuur & PFDcA & PFDA & $335-76-2$ \\
\hline Perfluor-n-dodecaanzuur & PFDoA & PFDoA & $307-55-1$ \\
\hline Perfluordecaansulfonaat & PFDS & PFDS & $335-77-3$ \\
\hline Perfluor-n-heptaanzuur & PFHpA & PFHpA & $375-85-9$ \\
\hline Perfluorheptaansulfonaat & PFHpS & PFHpS & $375-92-8$ \\
\hline Perfluor-n-hexaanzuur & PFHxA & PFHxA & $307-24-4$ \\
\hline Perfluorhexaansulfonaat & PFHxS & PFHxS & $355-46-4$ \\
\hline Perfluor-n-nonaanzuur & PFNA & PFNA & $375-95-1$ \\
\hline Perfluoroctaanzuur & PFOA & PFOA & $335-67-1$ \\
\hline Perfluoroctaansulfonaat & PFOS & PFOS & $1763-23-1$ \\
\hline Perfluor-n-pentaanzuur & PFPeA & PFPA & $2706-90-3$ \\
\hline Perfluortetradecaanzuur & PFTeA & PFTeDA & $376-06-7$ \\
\hline Perfluortridecaanzuur & PFTrA & PFTDA & $72629-94-8$ \\
\hline Perfluorundecaanzuur & PFUnA & PFUdA & $2058-94-8$ \\
\hline
\end{tabular}

In paragraaf 3.3.1 t/m 3.3.7 worden de Interne Standaard Werkvoorschriften (ISW's) vermeld die door Wageningen Marine Research gebruikt worden.

\subsubsection{PCB's en OCP's}

De stofgroepen PCB's en OCP worden in plaats van de traditionele methode bepaald door een vernieuwde methode. De traditionele methode bestaat uit soxhlet extractie, gevolgd door een vetverwijderingstap met behulp van een tweevoudige kolomchromatografische scheiding, waarna de analyse plaatsvindt met behulp van GC-ECD. Bij de vernieuwde methode worden de monsters opgewerkt door middel van een ASE-extractie. De halogeenverbindingen worden door middel van inline vetverwijdering mbv florisil geïsoleerd, waarna analyse plaatsvindt met behulp van gaschromatografie. De monsters worden gemeten tegen een kalibratiecurve en gedetecteerd met GCMS.

De methode is vastgelegd in Wageningen Marine Research ISW 2.10.3.050 "Dierlijk weefsel. Bepalen van het gehalte aan polychloorbifenylen (PCB) na ASE-extractie;(GC-MS) en "Dierlijk weefsel. Bepalen van het gehalte aan organochloorbestrijdingsmiddelen (OCP) na ASE-extractie; GC-MS" en staat op de scope van de Raad voor Accreditatie onder testlaboratoriumnummer L097, verrichting nummer 20 voor zowel de PCB als OCP.

\subsubsection{Cadmium, zink, koper en lood uitgevoerd door TNO Triskelion}

Een deel van het monster wordt in duplo ontsloten met salpeterzuur en waterstofperoxide, volgens TNO Triskelion voorschrift TRIS/LSP/108. In de verkregen oplossing wordt het gehalte aan cadmium, koper, lood en zink bepaald m.b.v. ICP-MS, volgens voorschrift TRIS/LSP/055 en TRIS/LSP/108. De kwantificering vindt plaats aan de hand van externe kalibratiestandaarden en om te corrigeren voor fluctuaties in de apparatuur wordt gebruik gemaakt van een interne standaard (rhodium). TNO Triskelion is geaccrediteerd door de Raad voor Accreditatie voor genoemde metalen (testlaboratoriumnummer L546, verrichting nummer 30).

\subsubsection{Droge stof}

Voor de bepaling van het droge stofgehalte wordt het gewogen monster gemengd met een oppervlakte vergrotende stof, vervolgens gedroogd in een stoof ( $105^{\circ} \mathrm{C}, 3$ uur) en na afkoelen in een exsiccator teruggewogen.

De methode is vastgelegd in Wageningen Marine Research ISW 2.10.3.011 "Dierlijk weefsel. Bepalen van het gehalte aan vocht; gravimetrie" staat op de scope van de Raad voor Accreditatie onder testlaboratoriumnummer L097, verrichting nummer 2. 
Indien zeer weinig monstermateriaal voorhanden is, zoals bij de schollevers soms het geval is, wordt de bepaling in enkelvoud uitgevoerd.

\subsubsection{Vet}

De totaal vet bepaling geschiedt volgens een aangepaste versie van de Bligh en Dyer methode, gebaseerd op een koude chloroform-methanol extractie.

De methode is vastgelegd in Wageningen Marine Research ISW 2.10.3.002 "Dierlijk weefsel. Bepalen van het gehalte aan vet volgens Bligh and Dyer; gravimetrie" en staat op de scope van de Raad voor Accreditatie onder testlaboratoriumnummer L097, verrichting nummer 1.

De bepaling van vrij extraheerbaar vet wordt uitgevoerd als onderdeel van de PCB analyse. Na de Soxhlet extractie wordt een deel van het extract drooggedampt en het residu gewogen. De bepaling van vrij extraheerbaar vet staat niet op de scope van de Raad voor Accreditatie.

\subsubsection{PBDE'S/HBCD}

Het analysemonster wordt gehomogeniseerd en het vocht wordt met natriumsulfaat verwijderd. De gebromeerde vlamvertragers worden met behulp van een Soxhlet extractie met pentaan/dichloormethaan opgelost. Het extract wordt met zwavelzuur behandeld om eventuele verontreinigingen en vet te verwijderen. Hierna wordt het extract verder gezuiverd met behulp van silicagelkolommen. De uiteindelijke bepaling wordt uitgevoerd met capillaire gaschromatografie en massa selectieve detectie.

De methode is vastgelegd in Wageningen Marine Research ISW 2.10.3.017 "Dierlijk weefsel. Bepalen van het gehalte aan gebromeerde vlamvertragers na extractie; GC-NCI-MS" en staat op de scope van de Raad voor Accreditatie onder testlaboratoriumnummer L097, verrichting nummer 8.

Aangezien PBDE154 een overlap heeft met BB153, wordt de som van beide componenten gerapporteerd.

\subsubsection{Perfluorverbindingen (PFAS)}

De analyse van perfluorverbindingen in de monsters wordt als volgt uitgevoerd (Kwadijk, C. et al., 2010): Na homogeniseren wordt 1-5 gram monster genomen en geëxtraheerd door middel van ultrasone extractie met acetonitril. Vervolgens worden de extracten gedroogd over een glasfilter met natriumsulfaat waarna er een opschoningsstap met actieve kool plaatsvindt. Het eindextract wordt geanalyseerd met behulp van LC-MS-ESI.

De methode is vastgelegd in Wageningen Marine Research ISW 2.10.3.045 "Dierlijk weefsel: Bepalen van het gehalte aan perfluorverbindingen na extractie; HPLC-ESI-MS" en staat op de scope van de Raad voor Accreditatie onder testlaboratoriumnummer L097, verrichting nummer 16.

\subsubsection{Kwik}

Voor de bepaling wordt het monster gedroogd en verast in een oven om kwik vrij te maken uit het monster. De vrijgekomen verbindingen worden d.m.v. zuurstof naar een catalyst tube geleid, waar oxidatie plaatsvindt en halogenen en stikstof- en zwaveloxiden worden verwijderd. De overige ontledingsproducten worden d.m.v. zuurstof naar een amalgamator geleid, waar de kwikverbindingen worden omgezet in metallisch kwik. Het gehalte aan kwik wordt vervolgens d.m.v. vlamloze atoomabsorptie spectrometrie bepaald. De monsters worden gemeten tegen een kalibratiecurve, die gemaakt is door het meten van verschillende hoeveelheden van een gecertificeerd referentiemateriaal. De methode is vastgelegd in Wageningen Marine Research ISW 2.10.3.025 "Dierlijk weefsel. Bepalen van het gehalte aan kwik m.b.v. SMS100 mercury analyser; vlamloze AAS" en staat op de scope van de Raad voor Accreditatie onder testlaboratoriumnummer L097, verrichting nummer 6. 


\subsection{Dataopslag en -registratie}

De gegenereerde data worden opgeslagen in LIMS. Een DONAR-script is beschikbaar dat ervoor zorgt dat de gegevens uit LIMS op de juiste manier in een DONAR-file terecht komen. De analyseresultaten uit het meetrapport die in LIMS worden geïmporteerd, worden gecontroleerd door een andere analist die bevoegd is voor de uitvoering van betreffende bepaling dan de uitvoerend analist. De Exceltabellen die uit LIMS worden gegenereerd en in het rapport worden opgenomen, worden door de uitvoerende analisten gecontroleerd op eventuele fouten en geparafeerd voor vrijgave. Van elk analyseresultaat wordt beoordeeld of het voldoet aan de kwaliteitscriteria die worden genoemd in het betreffende ISW, indien dit niet het geval is wordt de reden daarvan in het rapport vermeld. 


\section{Resultaten}

De resultaten vermeld in dit rapport zijn alleen van toepassing op de geanalyseerde monsters.

De exacte posities waarop de visserij heeft plaatsgevonden zijn weergegeven in bijlage 1 . De visserij verliep op alle drie de locaties goed. Op alle drie de locaties werden de voorgeschreven aantallen schollen gehaald (100 stuks en 3 reserve per locatie).

De chemische analyses hebben plaatsgevonden in het laboratorium locatie IJmuiden in de periode van januari t/m april 2017, en in het laboratorium van Triskelion in de periode februari, maart 2017.

De verzamelde gegevens en analyse-uitkomsten zijn in tabelvorm weergegeven in de bijlagen van dit rapport en zullen volgens opdracht tevens als Excel spreadsheet elektronisch worden verzonden. De chemische analyse-uitkomsten en bijbehorende biologische gegevens worden tevens als DIF file voor opslag in DONAR opgeleverd.

De tabellen worden gepresenteerd op aparte, volgens onderwerp gescheiden, bijlagen (zie tabel 3).

Tabel 3. Beschrijving van de Bijlagen

\begin{tabular}{|l|l|}
\hline Bijlage 1 & Visserijgegevens \\
\hline Bijlage 2.1 & Kaarten en posities \\
\hline Bijlage 3.1 & Biologische parameters vis PCB's, OCP's, PBDE's, perfluors en spoorelementen / Locatie West van IJmuiden (80 km): IJMWT80 \\
\hline Bijlage 3.2 & Biologische parameters vis PCB's, OCP's, PBDE's, perfluors en spoorelementen / Locatie NW-Terschelling (40km): TERSLNWT40 \\
\hline Bijlage 3.3 & Biologische parameters vis PCB's, OCP's, PBDE's, perfluors en spoorelementen / Locatie Doggersbank: DOGGBK \\
\hline Bijlage 4 & Metaalgehalten schollever, kwikgehalten scholspierweefsel \\
\hline Bijlage 5.1 & PCB's en OCP's gehalten schol / Locatie West van IJmuiden (80 km): IJMWT80 \\
\hline Bijlage 5.2 & PCB's en OCP's gehalten schol / Locatie NW-Terschelling (40km): TERSLNWT40 \\
\hline Bijlage 5.3 & PCB's en OCP's gehalten schol / Locatie Doggersbank: DOGGBK \\
\hline Bijlage 6 & PBDE gehalten \\
\hline Bijlage 7 & Perfluor gehalten / Locatie West van IJmuiden (80 km): IJMWT80 \\
\hline Bijlage 8.1 & Validatiegegevens analysemethoden / Resultaten referentiematerialen \\
\hline Bijlage 8.2 & Validatiegegevens analysemethoden / Resultaten Ringonderzoek Quasimeme in biota \\
\hline Bijlage 8.3 & Validatiegegevens analysemethoden / Rapportagegrenzen en meetonzekerheid \\
\hline
\end{tabular}

Ten aanzien van de resultaten van Wageningen Marine Research kan opgemerkt worden dat ze voldoen aan de kwaliteitseisen, zoals genoemd in 6 Kwaliteitsborging Wageningen Marine Research. Er zijn geen afwijkingen van de kwaliteitscriteria, zoals gesteld in de geaccrediteerde werkvoorschriften, geconstateerd, behalve voor de geaccrediteerde componenten CB-47 en CB-105 en de componenten PFTeA en PFTrA. De resultaten voor CB-47 en CB-105 zijn ivm co-elutie van een onbekende storende component, niet betrouwbaar bevonden en dus nb (kwaliteitscode 99) opgegeven met uitzondering van levermonster 6 (2016/2093) afkomstig uit IJmuiden (zie bijlage 5.1).

De gehaltes PFTeA en PFTrA waren niet nauwkeurig te meten in verband met interferentie, de gevonden waarde in de monsters zouden kleiner dan $5.6 \mu \mathrm{g} / \mathrm{kg}$. Door deze onnauwkeurigheid is er voor gekozen om de resultaten met nb (kwaliteitscode 99) op te geven.

De resultaten van de IRM's, gemeten door Wageningen Marine Research, zijn gecontroleerd met betrekking tot overschrijdingen van de 2s- en 3s-grenzen van de door Wageningen Marine Research intern gehanteerde kwaliteitscontrolekaarten voor de betreffende elementen. Dit is weergegeven in bijlage 8.1. Indien de 3s-grens wordt overschreden wordt daarop, vastgelegd in ons kwaliteitssysteem, adequaat actie ondernomen. Bijlage 8.1 toont echter dat aan de metingen, in 2016 uitgevoerd door Wageningen Marine Research in de IRM's, de kwalificatie goed kan worden toegekend.

De resultaten van Quasimeme ringonderzoeken zijn weergegeven in bijlage 8.2.

Indien een z-score de kwalificatie 'unsatisfactory' heeft gekregen wordt daarop, vastgelegd in ons kwaliteitssysteem, adequaat actie ondernomen. Hierop vindt jaarlijks controle plaats door de Raad voor Accreditatie. 
De betekenissen van de kwalificaties, zoals door Quasimeme toegekend, zijn als volgt:

Satisfactory:

$|Z|<2$, resultaat voldoet

Unsatisfactory:

$|Z|>3$, resultaat voldoet niet (adequate actie vereist)

Questionable:

$|Z|<3$, resultaat is twijfelachtig (geen actie vereist)

Consistent:

er is een waarde $(x)<$ rapportagegrens door het deelnemend lab

gerapporteerd, deze waarde was in overeenstemming met de assigned value

Inconsistent:

(consensus waarde), bv. $<0.03$ gerapporteerd, terwijl assigned value 0.02 is

er is een waarde $(x)<$ rapportagegrens door het deelnemend lab

gerapporteerd, deze waarde was niet in overeenstemming met de assigned

value (consensus waarde), bv. $<0.03$ gerapporteerd, terwijl assigned value

0.06 is

Blanc:

geen z-score bepaald door Quasimeme (mogelijke oorzaken: te weinig

laboratoria hebben resultaten gerapporteerd of de spreiding van de resultaten tussen de laboratoria onderling was te groot)

In 2016 is aan twee ringonderzoekrondes van Quasimeme deelgenomen (de labcode van Wageningen Marine Research is Q127).

De ringonderzoeken zijn binnen ons kwaliteitssysteem geëvalueerd en waar nodig zijn passende maatregelen genomen.

T.a.v. de toetsingscriteria op de resultaten van TNO Triskelion kan het volgende gezegd worden: Wageningen Marine Research hanteert een maximum toelaatbare rsd van $15 \%$ voor metalen tussen de duplowaarden van een monster, geanalyseerd door TNO Triskelion. De resultaten van het oude IRM van WMR, gemeten door TNO Triskelion, voldoen niet aan de gestelde eisen. De duplo verschillen zijn te hoog voor koper en lood. Ook bij heranalyse van het IRM werden te hoge duplowaarden vastgesteld. Dit criterium voor duploverschillen werd dit jaar voor geen enkel scholmonster overschreden.

Ook voldoen de analyses aan de gestelde eisen van het Triskelion kwaliteitssysteem, TNO Triskelion heeft alle resultaten van de metaalanalyses onder Q (ISO 17025 accreditatie) gerapporteerd.

De analyses worden daarom onder $\mathrm{Q}$ gerapporteerd in dit rapport.

TNO Triskelion neemt niet deel aan de ringonderzoeken van Quasimeme, de kwaliteit van hun analyses wordt echter wel geborgd door deelname aan andere ringonderzoeken, nl. die van FAPAS en IRMM.

In bijlage 8.3 zijn de rapportagegrenzen en meetonzekerheden weergegeven.

De rapportagegrenzen voor de anorganische componenten en voor de metalen zijn vaste rapportagegrenzen die zijn vastgesteld uit de historie van de blanco bepalingen.

De rapportagegrenzen voor de organische componenten worden vastgesteld aan de hand van de laagst gemeten standaard.

De rapportagegrens is afhankelijk van de hoeveelheid ingewogen monster en is dus eigenlijk voor ieder monster verschillend, de compromis rapportagegrenzen zijn in bijlage 8.3 weergegeven. De RMS (root mean square) wordt berekend volgens NEN 7779 als basis voor de gecombineerde meetonzekerheid (standard uncertainty) uit de resultaten van verschillende ringonderzoeken (verschillende matrices) van meerdere rondes $(n>8)$. De relatieve uitgebreide meetonzekerheid (expanded uncertainty) is gedefinieerd als twee maal de relatieve standard uncertainty. De relative standard uncertainty is weergegeven in bijlage 8.3. Hierin zijn de reproduceerbaarheid, de tussenmonster-spreiding en de methode juistheid verwerkt. Eventuele inhomogeniteit van het monster is hier niet in verwerkt, maar is bij ringonderzoekmonsters niet van toepassing.

Voor de rapportage aan OSPAR dient bij iedere meetwaarde de expanded uncertainty (95\% betrouwbaarheidsinterval) berekend te worden. De expanded uncertainty is gedefinieerd als tweemaal de standaard deviatie. Voor OSPAR dient dus een absolute meetonzekerheid gerapporteerd te worden. De berekening van de absolute expanded uncertainty is gebaseerd op onderstaande formules uit de OSPAR guideline voor de bepaling van de meetonzekerheid. De relative standard uncertainty (uitgedrukt in \%) wordt door Wageningen Marine Research als maat voor de vc gehanteerd. In bijlage 
8.3 zijn zowel de relative standard uncertainty $(=\mathrm{vc})$ als de constant error $(=\mathrm{dc})$ opgenomen. Beide dienen als input in de formules voor de berekening van de absolute expanded uncertainty.

Formules uit de OSPAR quideline:

$s_{C}=\sqrt{d_{C}^{2}+\left(\frac{v_{c}}{100}\right)^{2} C^{2}}$

waarin:

$\mathrm{S}_{\mathrm{c}}=$ standard deviation (eenheid = eenheid van concentratie component)

$\mathrm{d}_{\mathrm{c}}=$ "combined constant error" (eenheid = eenheid van concentratie component)

$\mathrm{v}_{\mathrm{c}}=$ variatie coëfficiënt (eenheid $=$ percentage)

$\mathrm{C}=$ concentratie van de component in het monster (meetwaarde)

$U_{c}=2 S_{c}$

waarin:

$\mathrm{U}_{\mathrm{c}}=$ (absolute) expanded uncertainty (eenheid = eenheid van concentratie component)

Voor componenten waarvoor geen deelname plaatsvindt aan ringonderzoeken is, indien mogelijk, de meetonzekerheid vastgesteld op basis van juistheidsbepaling en monsterinhomogeniteit. Voor componenten waarvoor zowel geen ringonderzoeken als geen referentiematerialen voorhanden zijn, kan de meetonzekerheid niet worden vastgesteld. Voor componenten waarvoor het aantal deelgenomen rondes aan ringonderzoeken minder bedraagt dan 8, kan nog geen meetonzekerheid worden vastgesteld volgens NEN 7779. 


\section{Aanbevelingen}

Aanbevolen wordt, om in het kader van de Kaderrichtlijn Marien (KRM), die componenten aan het monitoringprogramma toe te voegen waarvoor een Milieukwaliteitsnorm (MKN) in biota is vastgesteld (zie richtlijn 2011/0429 (COD), 31/01/2012. Voorstel voor een RICHTLIJN VAN HET EUROPEES PARLEMENT EN DE RAAD tot wijziging van Richtlijnen 2000/60/EG en 2008/105/EG betreffende prioritaire stoffen op het gebied van het waterbeleid).

Geadviseerd wordt naast de component heptachloor ook de componenten a-HEPO en $\beta$-HEPO te bepalen, aangezien EQS (Environmental Quality Standards) voor deze stoffen in biota zijn vastgesteld die worden vermeld in Richtlijn 2013/39/EU van 12 augustus 2013 tot wijziging van Richtlijn 2000/60/EG en Richtlijn 2008/105/EG wat betreft prioritaire stoffen op het gebied van waterbeleid. Dit geldt tevens voor de stoffen dicofol, HBCD en de perfluorverbindingen. Genoemde richtlijn is gepubliceerd in het EU-Publicatieblad en wordt rechtsgeldig vanaf 2018. Uiterlijk dan moeten de stoffen uit deze richtlijn worden gemonitord, maar het is aan te bevelen nu al inzicht te krijgen in de gehalten van deze stoffen. 


\section{$6 \quad$ Kwaliteitsborging}

Het chemisch laboratorium te IJmuiden beschikt over een NEN-EN-ISO/IEC 17025:2005 accreditatie voor testlaboratoria met nummer L097. Deze accreditatie is geldig tot 1 april 2021 en is voor het eerst verleend op 27 maart 1997; deze accreditatie is verleend door de Raad voor Accreditatie. Het chemisch laboratorium heeft hierdoor aangetoond in staat te zijn op technisch bekwame wijze valide resultaten te leveren en te werken volgens de IS017025 norm. De scope (L097) met de geaccrediteerde analysemethoden is te vinden op de website van de Raad voor Accreditatie (www.rva.nl).

Op grond van deze accreditatie is het kwaliteitskenmerk $\mathrm{Q}$ toegekend aan resultaten van componenten die op de scope zijn vermeld, mits aan alle kwaliteitseisen is voldaan. Het kwaliteitskenmerk $\mathrm{Q}$ staat vermeld in de tabellen met de onderzoeksresultaten. Indien het kwaliteitskenmerk $Q$ niet staat vermeld is de reden hiervan vermeld.

De kwaliteit van de analysemethoden wordt op verschillende manieren gewaarborgd:

- $\quad$ Bij iedere meetserie wordt een eerstelijnscontrole uitgevoerd: de resultaten van elke (serie van) meting(en) worden gecontroleerd door het gebruik van gecertificeerd en/of intern referentiemateriaal. Deze gegevens worden in kwaliteitscontrolekaarten bijgehouden. De "gecertificeerde" gehalten en de waarden van de waarschuwingsgrens (tweemaal standaarddeviatie) van de gebruikte referentiematerialen zijn weergegeven in bijlage 8.1.

- $\quad$ De juistheid van de analysemethoden wordt regelmatig getoetst door deelname aan ringonderzoeken waaronder die georganiseerd door QUASIMEME (derdelijnscontrole). Resultaten van de rondes zijn weergegeven in bijlage 8.2. Indien geen ringonderzoek voorhanden is, wordt een tweedelijnscontrole (blind monster) uitgevoerd.

- Naast de lijnscontroles worden de volgende algemene kwaliteitscontroles uitgevoerd:

- Blanco onderzoek

- $\quad$ Terugvinding (recovery)

- $\quad$ Interne standaard voor borging opwerkmethode

- $\quad$ Injectie standaard

- $\quad$ Gevoeligheid

Alle controles staan beschreven in Wageningen Marine Research ISW 2.10.2.105.

Indien sprake is van onbeheerste kwaliteit worden passende maatregelen genomen waarop jaarlijks controle plaatsvindt door de RvA.

Op speciaal verzoek van RWS zijn ook rapportagegrenzen en meetonzekerheden per component gerapporteerd. Deze zijn weergegeven in bijlage 8.3.

Daarnaast beschikt Wageningen Marine Research over een ISO 9001:2008 gecertificeerd kwaliteitsmanagementsysteem (certificaatnummer: 187378-2015-AQ-NLD-RvA). Dit certificaat is geldig tot 15 september 2018. De organisatie is gecertificeerd sinds 27 februari 2001. De certificering is uitgevoerd door DNV Certification B.V.

TNO Triskelion te Zeist

Het TNO laboratorium beschikt over een geldig ISO/IEC 17025 certificaat voor testlaboratoria met nummer L546 en is geaccrediteerd voor de bepaling van de te analyseren metalen arseen, cadmium, chroom, koper, lood en zink in vismatrix. De scoop is te vinden op de website van de Raad voor Accreditatie www.rva.nl en is geldig tot 1 november 2020.

Om de kwaliteit van de analysen te waarborgen en eventuele trendbreuk met metingen van voorgaande jaren inzichtelijk te maken is door Wageningen Marine Research een intern referentiemateriaal (IRM) meegestuurd. 
Het IRM (gevriesdroogde schol) is bij iedere meetserie scholmonsters geanalyseerd.

Ten aanzien van de resultaten past Wageningen Marine Research de volgende toetsingscriteria toe: De gehalten in het IRM worden gecontroleerd met betrekking tot overschrijdingen van de 2s- en 3sgrenzen van de door Wageningen Marine Research intern gehanteerde kwaliteitscontrolekaarten voor de betreffende elementen. Wat betreft deze kwaliteitscontrolekaarten is een grote historie opgebouwd en hierop heeft jaarlijks een controle plaatsgevonden door de Raad van Accreditatie.

Indien er in een serie een overschrijding blijkt te zijn van boven gestelde eisen, zal TNO Triskelion overgaan tot opnieuw analyseren van de betreffende serie monsters voor het metaal waarvoor de overschrijding heeft plaatsgevonden. 


\section{Verantwoording}

Rapport C028/17

Projectnummer: 4316100055

Dit rapport is met grote zorgvuldigheid tot stand gekomen. De wetenschappelijke kwaliteit is intern getoetst door een collega-onderzoeker en het verantwoordelijk lid van het managementteam van Wageningen Marine Research

Akkoord:

Dr. Michiel Kotterman

Onderzoeker

Handtekening:

Datum:

21-07-2017

Akkoord:

Dr. ir. T.P. Bult

Handtekening:

Datum:

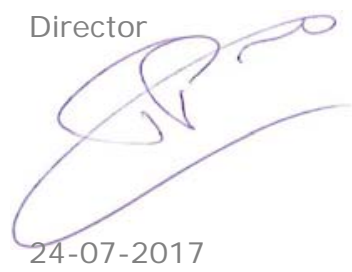


Bijlagen rapport C028.17 JAMP Schol: 1 t/m 8.3 
JAMP Schol 2016 / Bijlage 1: Visserijgegevens

Detail visserii

\begin{tabular}{|c|c|c|c|}
\hline & $\begin{array}{l}\text { Locatie West van } \\
\text { IJmuiden }(80 \mathrm{~km}) \text { : } \\
\text { IJMWT80 }\end{array}$ & $\begin{array}{c}\text { Locatie NW- } \\
\text { Terschelling }(40 \mathrm{~km}) \text { : } \\
\text { TERSLNWT40 }\end{array}$ & $\begin{array}{c}\text { Locatie Doggersbank: } \\
\text { DOGGBK }\end{array}$ \\
\hline Periode & $5-9-2016$ & $22 / 08 / 2016$ & $7-9-2016$ \\
\hline Positie & $\begin{array}{l}52 ' 24.5 \mathrm{NB} \\
03^{\prime} 19.2 \mathrm{OL}\end{array}$ & $\begin{array}{l}53 ' 36.611 \mathrm{NB} \\
04 ' 29.556 \mathrm{OL}\end{array}$ & $\begin{array}{l}55^{\prime} 13.98 \mathrm{NB} \\
03^{\prime} 03.90 \mathrm{OL}\end{array}$ \\
\hline Schip & Tridens & Tridens & Tridens \\
\hline Vistuig & 8 meter boomkor & 8 meter boomkor & 8 meter boomkor \\
\hline Verloop visserij & Goed & Goed & Goed \\
\hline
\end{tabular}




\section{JAMP Schol 2016 / Bijlage 2: Kaarten en posities}

Locatie West van IJmuiden $(80 \mathrm{~km})$ : IJMWT80

Locatie NW-Terschelling (40km): TERSLNWT40

Locatie Doggersbank: DOGGBK

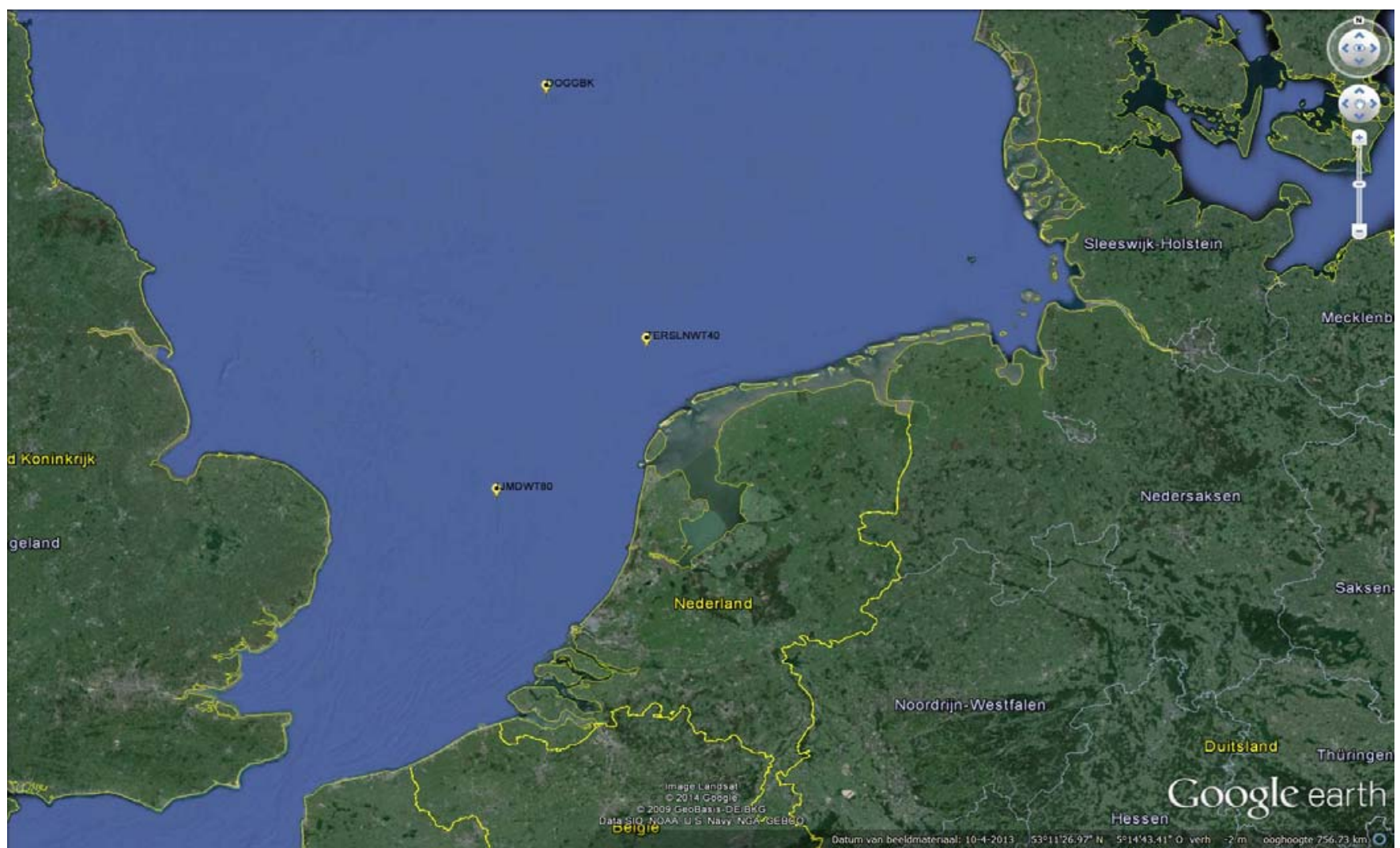


JAMP Schol 2016 / Bijlage 3.1: Biologische parameters vis PCB's, OCP's, PBDE's, perfluors en spoorelementen

Locatie West van IJmuiden $(80 \mathrm{~km})$ : IJMWT80

Vis voor PCBs, OCPs, PBDEs, perfluors en spoorelementen analyses, (gezonde vrouwen)

Analyse nrs

PCB's, OCP's, PBDE's en perfluors

\begin{tabular}{|l|c|c|c|c|c|}
\hline Heel & 6 & 7 & 8 & 9 & 10 \\
\hline Lever & $2016 / 2078$ & $2016 / 2079$ & $2016 / 2080$ & $2016 / 2081$ & $2016 / 2082$ \\
\hline
\end{tabular} \begin{tabular}{|l|l|l|l|l|l|}
\hline Lever & $2016 / 2093$ & $2016 / 2094$ & $2016 / 2095$ & $2016 / 2096$ & $2016 / 2097$ \\
\hline
\end{tabular}

\begin{tabular}{|c|c|c|c|c|c|}
\hline Analysenr. & $\begin{array}{l}\text { Visnr. } \\
\text { (heel) }\end{array}$ & $\begin{array}{l}\text { Lengte } \\
(\mathrm{mm})\end{array}$ & $\begin{array}{l}\text { Dicht } \\
\text { gewicht } \\
\text { (g) }\end{array}$ & $\begin{array}{c}\text { Leeftijd } \\
\text { (jaar) }\end{array}$ & $\begin{array}{l}\text { Lever- } \\
\text { gewicht } \\
\text { (g) }\end{array}$ \\
\hline \multirow[t]{10}{*}{ Heel } & 51 & 198 & 72 & 2 & 0.4 \\
\hline & 52 & 190 & 64 & 2 & 0.3 \\
\hline & 53 & 207 & 80 & 2 & 0.7 \\
\hline & 54 & 233 & 113 & 2 & 0.8 \\
\hline & 55 & 198 & 76 & 2 & 0.3 \\
\hline & 56 & 197 & 80 & 1 & 0.4 \\
\hline & 57 & 232 & 105 & 3 & 1.3 \\
\hline & 58 & 238 & 126 & 3 & 0.8 \\
\hline & 59 & 220 & 95 & 2 & 0.7 \\
\hline & 60 & 254 & 145 & 3 & 0.7 \\
\hline \multirow[t]{2}{*}{$2016 / 2078$} & Gem & 217 & 95.5 & 2.2 & 0.6 \\
\hline & Stdev & 22 & 26.0 & 0.6 & 0.3 \\
\hline Analysenr. & $\begin{array}{l}\text { Visnr. } \\
\text { (heel) }\end{array}$ & $\begin{array}{l}\text { Lengte } \\
(\mathrm{mm})\end{array}$ & $\begin{array}{c}\text { Dicht } \\
\text { gewicht } \\
\text { (g) }\end{array}$ & $\begin{array}{c}\text { Leeftijd } \\
\text { (jaar) }\end{array}$ & $\begin{array}{l}\text { Lever- } \\
\text { gewicht } \\
\text { (g) }\end{array}$ \\
\hline \multirow[t]{10}{*}{ Heel } & 61 & 202 & 68 & 2 & 0.5 \\
\hline & 62 & 217 & 94 & 2 & 0.5 \\
\hline & 63 & 204 & 77 & 2 & 0.5 \\
\hline & 64 & 237 & 142 & 1 & 1.2 \\
\hline & 65 & 217 & 92 & 1 & 0.7 \\
\hline & 66 & 232 & 111 & 3 & 0.8 \\
\hline & 67 & 197 & 73 & 2 & 0.2 \\
\hline & 68 & 208 & 77 & 2 & 0.4 \\
\hline & 69 & 193 & 67 & 1 & 0.4 \\
\hline & 70 & 207 & 78 & 2 & 0.4 \\
\hline \multirow[t]{2}{*}{$2016 / 2079$} & Gem & 211 & 87.8 & 1.8 & 0.6 \\
\hline & Stdev & 14 & 23.4 & 0.6 & 0.3 \\
\hline Analysenr. & $\begin{array}{l}\text { Visnr. } \\
\text { (heel) }\end{array}$ & $\begin{array}{l}\text { Lengte } \\
(\mathrm{mm})\end{array}$ & $\begin{array}{l}\text { Dicht } \\
\text { gewicht } \\
\text { (g) }\end{array}$ & $\begin{array}{c}\text { Leeftijd } \\
\text { (jaar) }\end{array}$ & $\begin{array}{l}\text { Lever- } \\
\text { gewicht } \\
\text { (g) }\end{array}$ \\
\hline \multirow[t]{10}{*}{ Heel } & 71 & 223 & 102 & 3 & 0.6 \\
\hline & 72 & 207 & 78 & 3 & 0.2 \\
\hline & 73 & 189 & 67 & 2 & 0.4 \\
\hline & 74 & 195 & 76 & 2 & 0.5 \\
\hline & 75 & 196 & 76 & 1 & 0.5 \\
\hline & 76 & 203 & 77 & 2 & 0.4 \\
\hline & 77 & 188 & 66 & 1 & 0.3 \\
\hline & 78 & 214 & 89 & 2 & 0.5 \\
\hline & 79 & 212 & 86 & 2 & 0.3 \\
\hline & 80 & 193 & 69 & 2 & 0.4 \\
\hline \multirow[t]{2}{*}{$2016 / 2080$} & Gem & 202 & 78.6 & 2.0 & 0.4 \\
\hline & Stdev & 12 & 11.2 & 0.7 & 0.1 \\
\hline
\end{tabular}

Analyse nrs

spoorelementen

\begin{tabular}{|l|c|c|c|c|c|}
\multicolumn{1}{c|}{} & 1 & 2 & 3 & 4 & 5 \\
\hline Heel & $2016 / 2073$ & $2016 / 2074$ & $2016 / 2075$ & $2016 / 2076$ & $2016 / 2077$ \\
\hline & $2016 / 2083$ & $2016 / 2084$ & $2016 / 2085$ & $2016 / 2086$ & $2016 / 2087$ \\
\hline
\end{tabular}

\begin{tabular}{|l|l|l|l|l|l|l|}
\hline Filet & $2016 / 2083$ & $2016 / 2084$ & $2016 / 2085$ & $2016 / 2086$ & $2016 / 2087$ \\
\hline
\end{tabular}

\begin{tabular}{|l|l|l|l|l|l|}
\hline Lever & $2016 / 2088$ & $2016 / 2089$ & $2016 / 2090$ & $2016 / 2091$ & $2016 / 2092$ \\
\hline
\end{tabular}

\begin{tabular}{|c|c|c|c|c|c|}
\hline Analysenr. & Visnr. & Lengte & $\begin{array}{c}\text { Dicht } \\
\text { gewicht } \\
(\mathrm{g})\end{array}$ & $\begin{array}{c}\text { Leeftijd } \\
\text { (jaar) }\end{array}$ & $\begin{array}{c}\text { Lever- } \\
\text { gewicht } \\
(\mathrm{g})\end{array}$ \\
\hline \multirow{4}{*}{ Heel } & 1 & 298 & 213 & 3 & 1.0 \\
\cline { 2 - 6 } & 2 & 206 & 80 & 2 & 0.4 \\
\cline { 2 - 6 } & 3 & 218 & 102 & 1 & 0.3 \\
\cline { 2 - 6 } & 4 & 225 & 96 & 2 & 0.8 \\
\cline { 2 - 6 } & 5 & 187 & 63 & 1 & 0.6 \\
\cline { 2 - 6 } & 6 & 206 & 80 & 2 & 0.6 \\
\cline { 2 - 6 } & 7 & 208 & 89 & 2 & 0.6 \\
\cline { 2 - 6 } & 8 & 197 & 74 & 2 & 0.5 \\
\cline { 2 - 6 } & 9 & 270 & 177 & 4 & 1.5 \\
\cline { 2 - 6 } & 10 & 244 & 125 & 3 & 1.0 \\
\cline { 2 - 6 } & Gem & 226 & 109.7 & 2.2 & 0.7 \\
\cline { 2 - 6 } & Stdev & 35 & 48.6 & 0.9 & 0.4 \\
\hline
\end{tabular}

\begin{tabular}{|c|c|c|c|c|c|}
\hline Analysenr. & Visnr. & Lengte & $\begin{array}{c}\text { Dicht } \\
\text { gewicht } \\
(\mathrm{g})\end{array}$ & $\begin{array}{c}\text { Leeftijd } \\
\text { (jaar) }\end{array}$ & $\begin{array}{c}\text { Lever- } \\
\text { gewicht } \\
(\mathrm{g})\end{array}$ \\
\hline \multirow{4}{*}{ Heel } & 11 & 212 & 85 & 2 & 0.4 \\
\cline { 2 - 6 } & 12 & 211 & 78 & 2 & 0.6 \\
\cline { 2 - 6 } & 13 & 268 & 166 & 3 & 1.4 \\
\cline { 2 - 6 } & 14 & 254 & 165 & 3 & 1.1 \\
\cline { 2 - 6 } & 15 & 279 & 179 & 3 & 1.4 \\
\cline { 2 - 6 } & 16 & 215 & 85 & 2 & 0.6 \\
\cline { 2 - 6 } & 17 & 278 & 191 & 3 & 1.5 \\
\cline { 2 - 6 } & 18 & 232 & 107 & 3 & 0.9 \\
\cline { 2 - 6 } & 19 & 192 & 66 & 2 & 0.6 \\
\cline { 2 - 6 } & 20 & 197 & 68 & 2 & 0.4 \\
\cline { 2 - 6 } & Gem & 234 & 119.1 & 2.5 & 0.9 \\
\cline { 2 - 6 } & Stdev & 33 & 50.0 & 0.5 & 0.4 \\
\hline
\end{tabular}

\begin{tabular}{|c|c|c|c|c|c|}
\hline Analysenr. & Visnr. & Lengte & $\begin{array}{c}\text { Dicht } \\
\text { gewicht } \\
(\mathrm{g})\end{array}$ & $\begin{array}{c}\text { Leeftijd } \\
\text { (jaar) }\end{array}$ & $\begin{array}{c}\text { Lever- } \\
\text { gewicht } \\
(\mathrm{g})\end{array}$ \\
\hline \multirow{4}{*}{ Heel } & 21 & 207 & 77 & 2 & 0.5 \\
\cline { 2 - 6 } & 22 & 209 & 81 & 2 & 0.5 \\
\cline { 2 - 6 } & 23 & 186 & 63 & 1 & 0.4 \\
\cline { 2 - 6 } & 24 & 226 & 115 & 2 & 0.7 \\
\cline { 2 - 6 } & 25 & 206 & 86 & 2 & 0.6 \\
\cline { 2 - 6 } & 26 & 204 & 83 & 2 & 0.6 \\
\cline { 2 - 6 } & 27 & 215 & 83 & 2 & 0.5 \\
\cline { 2 - 6 } & 28 & 299 & 236 & 3 & 2.2 \\
\cline { 2 - 6 } & 29 & 222 & 101 & 2 & 0.7 \\
\cline { 2 - 6 } & 30 & 257 & 153 & 4 & 1.0 \\
\cline { 2 - 6 } & Gem & 223 & 107.6 & 2.2 & 0.8 \\
\cline { 2 - 6 } & Stdev & 32 & 51.7 & 0.8 & 0.5 \\
\hline
\end{tabular}

\begin{tabular}{|c|c|c|c|c|c|}
\hline Analysenr. & $\begin{array}{l}\text { Visnr. } \\
\text { (heel) }\end{array}$ & $\begin{array}{l}\text { Lengte } \\
(\mathrm{mm})\end{array}$ & $\begin{array}{l}\text { Dicht } \\
\text { gewicht } \\
\text { (g) }\end{array}$ & $\begin{array}{c}\text { Leeftijd } \\
\text { (jaar) }\end{array}$ & $\begin{array}{l}\text { Lever- } \\
\text { gewicht } \\
\text { (g) }\end{array}$ \\
\hline \multirow[t]{10}{*}{ Heel } & 81 & 270 & 173 & 3 & 0.8 \\
\hline & 82 & 237 & 116 & 2 & 0.4 \\
\hline & 83 & 204 & 79 & 3 & 0.5 \\
\hline & 84 & 294 & 226 & 4 & 1.5 \\
\hline & 85 & 205 & 81 & 3 & 0.6 \\
\hline & 86 & 257 & 153 & 3 & 1.1 \\
\hline & 87 & 271 & 196 & 3 & 2.2 \\
\hline & 88 & 207 & 83 & 3 & 0.6 \\
\hline & 89 & 201 & 77 & 2 & 0.3 \\
\hline & 90 & 205 & 73 & 2 & 0.3 \\
\hline \multirow[t]{2}{*}{$2016 / 2081$} & Gem & 235 & 125.7 & 2.8 & 0.8 \\
\hline & Stdev & 35 & 57.0 & 0.6 & 0.6 \\
\hline
\end{tabular}

\begin{tabular}{|c|c|c|c|c|c|}
\hline Analysenr. & Visnr. & Lengte & $\begin{array}{c}\text { Dicht } \\
\text { gewicht } \\
(\text { (heel) }\end{array}$ & $\begin{array}{c}\text { Leeftijd } \\
\text { (jaar) }\end{array}$ & $\begin{array}{c}\text { Lever- } \\
\text { gewicht } \\
(\mathrm{gm})\end{array}$ \\
\hline \multirow{4}{*}{ Heel } & 31 & 200 & 73 & 2 & 0.4 \\
\cline { 2 - 6 } & 32 & 188 & 65 & 2 & 0.4 \\
\cline { 2 - 6 } & 33 & 184 & 56 & 1 & 0.5 \\
\cline { 2 - 6 } & 34 & 200 & 73 & 2 & 0.4 \\
\cline { 2 - 6 } & 35 & 208 & 76 & 2 & 0.7 \\
\cline { 2 - 6 } & 36 & 196 & 66 & 2 & 0.4 \\
\cline { 2 - 6 } & 37 & 196 & 71 & 2 & 0.5 \\
\cline { 2 - 6 } & 38 & 256 & 157 & 3 & 1.2 \\
\cline { 2 - 6 } & 39 & 202 & 78 & 2 & 0.5 \\
\cline { 2 - 6 } & 40 & 240 & 112 & 2 & 1.0 \\
\cline { 2 - 6 } & Gem & 207 & 82.6 & 2.0 & 0.6 \\
\cline { 2 - 6 } & Stdev & 23 & 29.9 & 0.5 & 0.3 \\
\hline
\end{tabular}

\begin{tabular}{|c|c|c|c|c|c|}
\hline Analysenr. & Visnr. & Lengte & $\begin{array}{c}\text { Dicht } \\
\text { gewicht } \\
(\mathrm{g})\end{array}$ & $\begin{array}{c}\text { Leeftijd } \\
\text { (jaar) }\end{array}$ & $\begin{array}{c}\text { Lever- } \\
\text { gewicht } \\
(\mathrm{g})\end{array}$ \\
\hline \multirow{4}{*}{ Heel } & 91 & 229 & 110 & 3 & 0.5 \\
\cline { 2 - 6 } & 92 & 211 & 89 & 1 & 0.7 \\
\cline { 2 - 6 } & 93 & 231 & 114 & 2 & 0.8 \\
\cline { 2 - 6 } & 94 & 275 & 170 & 3 & 1.1 \\
\cline { 2 - 6 } & 95 & 266 & 182 & 3 & 1.4 \\
\cline { 2 - 6 } & 96 & 260 & 158 & 5 & 0.6 \\
\cline { 2 - 6 } & 97 & 237 & 121 & 2 & 0.4 \\
\cline { 2 - 6 } & 98 & 247 & 127 & 3 & 0.8 \\
\cline { 2 - 6 } & 99 & 204 & 83 & 1 & 0.7 \\
\cline { 2 - 6 } & 100 & 262 & 154 & 3 & 1.2 \\
\cline { 2 - 6 } & Gem & 242 & 130.8 & 2.6 & 0.8 \\
\cline { 2 - 6 } & Stdev & 24 & 33.9 & 1.2 & 0.3 \\
\hline
\end{tabular}

\begin{tabular}{|c|c|c|c|c|c|}
\hline Analysenr. & Visnr. & Lengte & $\begin{array}{c}\text { Dicht } \\
\text { gewicht } \\
(\mathrm{g})\end{array}$ & $\begin{array}{c}\text { Leeftijd } \\
\text { (jaar) }\end{array}$ & $\begin{array}{c}\text { Lever- } \\
\text { gewicht } \\
(\mathrm{g})\end{array}$ \\
\hline \multirow{4}{*}{ Heel } & 41 & 212 & 99 & 2 & 0.6 \\
\cline { 2 - 6 } & 42 & 227 & 90 & 2 & 0.6 \\
\cline { 2 - 6 } & 43 & 193 & 62 & 2 & 0.4 \\
\cline { 2 - 6 } & 44 & 193 & 67 & 2 & 0.4 \\
\cline { 2 - 6 } & 45 & 215 & 88 & 3 & 0.5 \\
\cline { 2 - 6 } & 46 & 234 & 103 & 2 & 0.4 \\
\cline { 2 - 6 } & 47 & 212 & 86 & 1 & 0.6 \\
\cline { 2 - 6 } & 48 & 241 & 125 & 3 & 1.9 \\
\cline { 2 - 6 } & 49 & 200 & 74 & 2 & 0.5 \\
\cline { 2 - 6 } & 50 & 201 & 73 & 2 & 0.3 \\
\cline { 2 - 6 } & Gem & 213 & 86.7 & 2.1 & 0.6 \\
\cline { 2 - 6 } & Stdev & 17 & 19.1 & 0.6 & 0.5 \\
\hline
\end{tabular}


JAMP Schol 2016 / Bijlage 3.2: Biologische parameters vis PCB's, OCP's, PBDE's, perfluors en spoorelementen

Locatie NW-Terschelling $(40 \mathrm{~km})$ : TERSLNWT40

Vis voor PCBs, OCPS, PBDEs, perfluors en spoorelementen analyses, (gezonde vrouwen)

Analyse nrs

PCB's, OCP's, PBDE's en perfluors

\begin{tabular}{|l|c|c|c|c|c|}
\multicolumn{1}{c|}{} & 6 & 7 & 8 & 9 & 10 \\
\hline Heel & $2016 / 2103$ & $2016 / 2104$ & $2016 / 2105$ & $2016 / 2106$ & $2016 / 2107$ \\
\hline
\end{tabular} \begin{tabular}{|l|l|l|l|l|l|}
\hline Lever & $2016 / 2118$ & $2016 / 2119$ & $2016 / 2120$ & $2016 / 2121$ & $2016 / 2122$ \\
\hline
\end{tabular}

\begin{tabular}{|c|c|c|c|c|c|}
\hline Analysenr. & $\begin{array}{l}\text { Visnr. } \\
\text { (heel) }\end{array}$ & $\begin{array}{l}\text { Lengte } \\
(\mathrm{mm})\end{array}$ & $\begin{array}{l}\text { Dicht } \\
\text { gewicht } \\
\text { (g) }\end{array}$ & $\begin{array}{c}\text { Leeftijd } \\
\text { (jaar) }\end{array}$ & $\begin{array}{l}\text { Lever- } \\
\text { gewicht } \\
\text { (g) }\end{array}$ \\
\hline \multirow{10}{*}{ Heel } & 51 & 222 & 104 & 2 & 1.0 \\
\hline & 52 & 266 & 162 & 3 & 1.5 \\
\hline & 53 & 197 & 72 & 1 & 0.5 \\
\hline & 54 & 261 & 166 & 2 & 1.0 \\
\hline & 55 & 212 & 96 & 2 & 0.7 \\
\hline & 56 & 228 & 106 & 2 & 0.4 \\
\hline & 57 & 193 & 68 & 2 & 0.7 \\
\hline & 58 & 178 & 56 & 2 & 0.4 \\
\hline & 59 & 187 & 60 & 2 & 0.9 \\
\hline & 60 & 194 & 72 & 2 & 0.7 \\
\hline \multirow[t]{2}{*}{$2016 / 2103$} & Gem & 214 & 96.2 & 2.0 & 0.8 \\
\hline & Stdev & 30 & 39.8 & 0.5 & 0.3 \\
\hline Analysenr. & $\begin{array}{l}\text { Visnr. } \\
\text { (heel) }\end{array}$ & $\begin{array}{l}\text { Lengte } \\
(\mathrm{mm})\end{array}$ & $\begin{array}{c}\text { Dicht } \\
\text { gewicht } \\
\text { (g) }\end{array}$ & $\begin{array}{c}\text { Leeftijd } \\
\text { (jaar) }\end{array}$ & $\begin{array}{l}\text { Lever- } \\
\text { gewicht } \\
\text { (g) }\end{array}$ \\
\hline \multirow[t]{10}{*}{ Heel } & 61 & 186 & 64 & 1 & 0.5 \\
\hline & 62 & 204 & 90 & 2 & 0.8 \\
\hline & 63 & 208 & 74 & 2 & 0.9 \\
\hline & 64 & 248 & 150 & 3 & 1.6 \\
\hline & 65 & 265 & 168 & 3 & 1.2 \\
\hline & 66 & 231 & 118 & 3 & 1.1 \\
\hline & 67 & 182 & 60 & 2 & 0.6 \\
\hline & 68 & 212 & 94 & 2 & 1.2 \\
\hline & 69 & 181 & 58 & 1 & 0.6 \\
\hline & 70 & 251 & 148 & 3 & 1.4 \\
\hline \multirow[t]{2}{*}{$2016 / 2104$} & Gem & 217 & 102.4 & 2.2 & 1.0 \\
\hline & Stdev & 31 & 41.1 & 0.8 & 0.4 \\
\hline Analysenr. & $\begin{array}{l}\text { Visnr. } \\
\text { (heel) }\end{array}$ & $\begin{array}{l}\text { Lengte } \\
(\mathrm{mm})\end{array}$ & $\begin{array}{l}\text { Dicht } \\
\text { gewicht } \\
\text { (g) }\end{array}$ & $\begin{array}{c}\text { Leeftijd } \\
\text { (jaar) }\end{array}$ & $\begin{array}{l}\text { Lever- } \\
\text { gewicht } \\
\text { (g) }\end{array}$ \\
\hline \multirow[t]{10}{*}{ Heel } & 71 & 252 & 166 & 3 & 1.9 \\
\hline & 72 & 254 & 158 & 3 & 1.8 \\
\hline & 73 & 248 & 140 & 3 & 1.0 \\
\hline & 74 & 247 & 154 & 3 & 2.1 \\
\hline & 75 & 298 & 244 & 3 & 1.6 \\
\hline & 76 & 261 & 188 & 3 & 3.2 \\
\hline & 77 & 277 & 180 & 3 & 1.4 \\
\hline & 78 & 222 & 114 & 2 & 1.2 \\
\hline & 79 & 253 & 148 & 2 & 2.0 \\
\hline & 80 & 211 & 98 & 2 & 0.7 \\
\hline \multirow[t]{2}{*}{$2016 / 2105$} & Gem & 252 & 159.0 & 2.7 & 1.7 \\
\hline & Stdev & 25 & 40.6 & 0.5 & 0.7 \\
\hline
\end{tabular}

Analyse nrs

spoorelementen

\begin{tabular}{|l|c|c|c|c|c|}
\multicolumn{1}{c|}{} & 1 & 2 & 3 & 4 & 5 \\
\hline Heel & $2016 / 2098$ & $2016 / 2099$ & $2016 / 2100$ & $2016 / 2101$ & $2016 / 2102$ \\
\hline & $2016 / 2108$ & $2016 / 2109$ & $2016 / 2110$ & $2016 / 2111$ & $2016 / 2112$ \\
\hline
\end{tabular}

\begin{tabular}{|l|l|l|l|l|l|l|}
\hline Filet & $2016 / 2108$ & $2016 / 2109$ & $2016 / 2110$ & $2016 / 2111$ & $2016 / 2112$ \\
\hline
\end{tabular}

\begin{tabular}{|l|l|l|l|l|l|}
\hline Lever & $2016 / 2113$ & $2016 / 2114$ & $2016 / 2115$ & $2016 / 2116$ & $2016 / 2117$ \\
\hline
\end{tabular}

\begin{tabular}{|c|c|c|c|c|c|}
\hline Analysenr. & Visnr. & Lengte & $\begin{array}{c}\text { Dicht } \\
\text { gewicht } \\
(\mathrm{g})\end{array}$ & $\begin{array}{c}\text { Leeftijd } \\
\text { (jaar) }\end{array}$ & $\begin{array}{c}\text { Lever- } \\
\text { gewicht } \\
(\mathrm{g})\end{array}$ \\
\hline \multirow{4}{*}{ Heel } & 1 & 224 & 110 & 3 & 1.2 \\
\cline { 2 - 6 } & 2 & 252 & 172 & 3 & 1.9 \\
\cline { 2 - 6 } & 3 & 243 & 142 & 3 & 2.1 \\
\cline { 2 - 6 } & 4 & 218 & 102 & 2 & 0.6 \\
\cline { 2 - 6 } & 5 & 216 & 106 & 1 & 0.5 \\
\cline { 2 - 6 } & 6 & 196 & 74 & 2 & 0.9 \\
\cline { 2 - 6 } & 7 & 278 & 202 & 3 & 1.8 \\
\cline { 2 - 6 } & 8 & 228 & 102 & 2 & 1.2 \\
\cline { 2 - 6 } & 9 & 241 & 126 & 2 & 1.2 \\
\cline { 2 - 6 } & 10 & 248 & 136 & 3 & 0.8 \\
\cline { 2 - 6 } & Gem & 234 & 127.2 & 2.4 & 1.2 \\
\cline { 2 - 6 } & Stdev & 23 & 37.6 & 0.7 & 0.6 \\
\hline
\end{tabular}

\begin{tabular}{|c|c|c|c|c|c|}
\hline Analysenr. & Visnr. & Lengte & $\begin{array}{c}\text { Dicht } \\
\text { gewicht } \\
(\mathrm{g})\end{array}$ & $\begin{array}{c}\text { Leeftijd } \\
\text { (jaar) }\end{array}$ & $\begin{array}{c}\text { Lever- } \\
\text { gewicht } \\
(\mathrm{g})\end{array}$ \\
\hline \multirow{4}{*}{ Heel } & 11 & 196 & 72 & 1 & 0.8 \\
\cline { 2 - 6 } & 12 & 177 & 56 & 1 & 0.4 \\
\cline { 2 - 6 } & 13 & 188 & 70 & 2 & 0.8 \\
\cline { 2 - 6 } & 14 & 223 & 110 & 2 & 0.9 \\
\cline { 2 - 6 } & 15 & 204 & 78 & 2 & 0.7 \\
\cline { 2 - 6 } & 16 & 234 & 126 & 3 & 1.2 \\
\cline { 2 - 6 } & 17 & 242 & 146 & 2 & 1.3 \\
\cline { 2 - 6 } & 18 & 197 & 80 & 2 & 0.9 \\
\cline { 2 - 6 } & 19 & 158 & 36 & 2 & 0.4 \\
\cline { 2 - 6 } & 20 & 162 & 40 & 1 & 0.3 \\
\cline { 2 - 6 } & Gem & 198 & 81.4 & 1.8 & 0.8 \\
\cline { 2 - 6 } & Stdev & 29 & 36.0 & 0.6 & 0.3 \\
\hline
\end{tabular}

\begin{tabular}{|c|c|c|c|c|c|}
\hline Analysenr. & Visnr. & Lengte & $\begin{array}{c}\text { Dicht } \\
\text { gewicht } \\
(\mathrm{g})\end{array}$ & $\begin{array}{c}\text { Leeftijd } \\
\text { (jaar) }\end{array}$ & $\begin{array}{c}\text { Lever- } \\
\text { gewicht } \\
(\mathrm{g})\end{array}$ \\
\hline \multirow{4}{*}{ Heel } & 21 & 182 & 74 & 1 & 0.6 \\
\cline { 2 - 6 } & 22 & 219 & 94 & 2 & 0.9 \\
\cline { 2 - 6 } & 23 & 217 & 106 & 1 & 1.2 \\
\cline { 2 - 6 } & 24 & 239 & 128 & 2 & 0.8 \\
\cline { 2 - 6 } & 25 & 188 & 66 & 1 & 0.5 \\
\cline { 2 - 6 } & 26 & 196 & 76 & 2 & 0.5 \\
\cline { 2 - 6 } & 27 & 172 & 56 & 1 & 0.4 \\
\cline { 2 - 6 } & 28 & 218 & 102 & 3 & 1.3 \\
\cline { 2 - 6 } & 29 & 161 & 48 & 1 & 0.5 \\
\cline { 2 - 6 } & 30 & 179 & 64 & 1 & 0.4 \\
\cline { 2 - 6 } & Gem & 197 & 81.4 & 1.5 & 0.7 \\
\cline { 2 - 6 } & Stdev & 25 & 25.3 & 0.7 & 0.3 \\
\hline
\end{tabular}

\begin{tabular}{|c|c|c|c|c|c|}
\hline Analysenr. & Visnr. & Lengte & $\begin{array}{c}\text { Dicht } \\
\text { gewicht } \\
(\mathrm{g})\end{array}$ & $\begin{array}{c}\text { Leeftijd } \\
\text { (jaar) }\end{array}$ & $\begin{array}{c}\text { Lever- } \\
\text { gewicht } \\
(\mathrm{g})\end{array}$ \\
\hline \multirow{4}{*}{ Heel } & 81 & 208 & 88 & 2 & 1.2 \\
\cline { 2 - 6 } & 82 & 283 & 216 & 4 & 1.6 \\
\cline { 2 - 6 } & 83 & 212 & 90 & 2 & 0.7 \\
\cline { 2 - 6 } & 84 & 223 & 104 & 2 & 1.2 \\
\cline { 2 - 6 } & 85 & 222 & 108 & 3 & 0.7 \\
\cline { 2 - 6 } & 86 & 226 & 128 & 2 & 1.2 \\
\cline { 2 - 6 } & 87 & 227 & 122 & 2 & 1.2 \\
\cline { 2 - 6 } & 88 & 262 & 196 & 3 & 2.1 \\
\cline { 2 - 6 } & 89 & 296 & 232 & 4 & 2.2 \\
\cline { 2 - 6 } & 90 & 234 & 116 & 2 & 1.0 \\
\cline { 2 - 6 } & Gem & 239 & 140.0 & 2.6 & 1.3 \\
\cline { 2 - 6 } & Stdev & 30 & 53.7 & 0.8 & 0.5 \\
\hline
\end{tabular}

\begin{tabular}{|c|c|c|c|c|c|}
\hline Analysenr. & Visnr. & Lengte & $\begin{array}{c}\text { Dicht } \\
\text { gewicht } \\
(\text { (heel) }\end{array}$ & $\begin{array}{c}\text { Leeftijd } \\
\text { (jaar) }\end{array}$ & $\begin{array}{c}\text { Lever- } \\
\text { gewicht } \\
(\mathrm{gm})\end{array}$ \\
\hline \multirow{4}{*}{ Heel } & 31 & 222 & 108 & 2 & 0.8 \\
\cline { 2 - 6 } & 32 & 276 & 186 & 3 & 2.6 \\
\cline { 2 - 6 } & 33 & 207 & 90 & 2 & 0.8 \\
\cline { 2 - 6 } & 34 & 184 & 68 & 1 & 0.4 \\
\cline { 2 - 6 } & 35 & 213 & 98 & 3 & 0.7 \\
\cline { 2 - 6 } & 36 & 168 & 48 & 1 & 0.4 \\
\cline { 2 - 6 } & 37 & 202 & 80 & 2 & 0.4 \\
\cline { 2 - 6 } & 38 & 273 & 192 & 3 & 1.5 \\
\cline { 2 - 6 } & 39 & 191 & 68 & 1 & 0.5 \\
\cline { 2 - 6 } & 40 & 222 & 100 & 2 & 1.1 \\
\cline { 2 - 6 } & Gem & 216 & 103.8 & 2.0 & 0.9 \\
\cline { 2 - 6 } & Stdev & 35 & 48.3 & 0.8 & 0.7 \\
\hline
\end{tabular}

\begin{tabular}{|c|c|c|c|c|c|}
\hline Analysenr. & Visnr. & Lengte & $\begin{array}{c}\text { Dicht } \\
\text { gewicht } \\
(\mathrm{g})\end{array}$ & $\begin{array}{c}\text { Leeftijd } \\
\text { (jaar) }\end{array}$ & $\begin{array}{c}\text { Lever- } \\
\text { gewicht } \\
(\mathrm{g})\end{array}$ \\
\hline \multirow{4}{*}{ Heel } & 91 & 243 & 124 & 3 & 1.3 \\
\cline { 2 - 6 } & 92 & 296 & 262 & 4 & 3.9 \\
\cline { 2 - 6 } & 93 & 277 & 218 & 4 & 1.8 \\
\cline { 2 - 6 } & 94 & 211 & 92 & 2 & 1.1 \\
\cline { 2 - 6 } & 95 & 221 & 108 & 2 & 1.1 \\
\cline { 2 - 6 } & 96 & 166 & 48 & 1 & 0.2 \\
\cline { 2 - 6 } & 97 & 213 & 100 & 2 & 1.0 \\
\cline { 2 - 6 } & 98 & 157 & 42 & 1 & 0.3 \\
\cline { 2 - 6 } & 99 & 213 & 96 & 2 & 1.0 \\
\cline { 2 - 6 } & 100 & 171 & 48 & 1 & 0.2 \\
\cline { 2 - 6 } & Gem & 217 & 113.8 & 2.2 & 1.2 \\
\cline { 2 - 6 } & Stdev & 46 & 72.8 & 1.1 & 1.1 \\
\hline
\end{tabular}

\begin{tabular}{|c|c|c|c|c|c|}
\hline Analysenr. & Visnr. & Lengte & $\begin{array}{c}\text { Dicht } \\
\text { gewicht } \\
(\mathrm{g})\end{array}$ & $\begin{array}{c}\text { Leeftijd } \\
\text { (jaar) }\end{array}$ & $\begin{array}{c}\text { Lever- } \\
\text { gewicht } \\
(\mathrm{g})\end{array}$ \\
\hline \multirow{4}{*}{ Heel } & 41 & 243 & 116 & 3 & 1.5 \\
\cline { 2 - 6 } & 42 & 289 & 248 & 4 & 2.6 \\
\cline { 2 - 6 } & 43 & 228 & 122 & 2 & 0.8 \\
\cline { 2 - 6 } & 44 & 268 & 190 & 3 & 1.4 \\
\cline { 2 - 6 } & 45 & 192 & 66 & 1 & 0.4 \\
\cline { 2 - 6 } & 46 & 281 & 212 & 4 & 1.6 \\
\cline { 2 - 6 } & 47 & 203 & 82 & 2 & 0.8 \\
\cline { 2 - 6 } & 48 & 213 & 86 & 2 & 0.8 \\
\cline { 2 - 6 } & 49 & 252 & 158 & 3 & 2.0 \\
\cline { 2 - 6 } & 50 & 266 & 172 & 3 & 1.5 \\
\cline { 2 - 6 } & Gem & 244 & 145.2 & 2.7 & 1.3 \\
\cline { 2 - 6 } & Stdev & 34 & 60.6 & 0.9 & 0.7 \\
\hline
\end{tabular}


JAMP Schol 2016 / Bijlage 3.3: Biologische parameters vis PCB's, OCP's, PBDE's, perfluors en spoorelementen

Locatie Doggersbank: DOGGBK

Vis voor PCBs, OCPs, PBDEs, perfluors en spoorelementen analyses, (gezonde vrouwen)

Analyse nrs

PCB's, OCP's, PBDE's en perfluors

\begin{tabular}{|l|c|c|c|c|c|}
\multicolumn{1}{c|}{} & 6 & 7 & 8 & 9 & 10 \\
\hline Heel & $2016 / 2128$ & $2016 / 2129$ & $2016 / 2130$ & $2016 / 2131$ & $2016 / 2132$ \\
\hline
\end{tabular} \begin{tabular}{|l|l|l|l|l|l|}
\hline Lever & $2016 / 2143$ & $2016 / 2144$ & $2016 / 2145$ & $2016 / 2146$ & $2016 / 2147$ \\
\hline
\end{tabular}

\begin{tabular}{|c|c|c|c|c|c|}
\hline Analysenr. & $\begin{array}{l}\text { Visnr. } \\
\text { (heel) }\end{array}$ & $\begin{array}{l}\text { Lengte } \\
(\mathrm{mm})\end{array}$ & $\begin{array}{l}\text { Dicht } \\
\text { gewicht } \\
\text { (g) }\end{array}$ & $\begin{array}{c}\text { Leeftijd } \\
\text { (jaar) }\end{array}$ & $\begin{array}{l}\text { Lever- } \\
\text { gewicht } \\
\text { (g) }\end{array}$ \\
\hline \multirow{10}{*}{ Heel } & 51 & 275 & 185 & 3 & 1.3 \\
\hline & 52 & 297 & 255 & 3 & 3.3 \\
\hline & 53 & 295 & 262 & 4 & 4.2 \\
\hline & 54 & 297 & 271 & 3 & 4.3 \\
\hline & 55 & 302 & 296 & 3 & 4.1 \\
\hline & 56 & 265 & 163 & 2 & 0.9 \\
\hline & 57 & 250 & 150 & 3 & 0.9 \\
\hline & 58 & 298 & 261 & 3 & 3.7 \\
\hline & 59 & 281 & 246 & 3 & 4.1 \\
\hline & 60 & 298 & 255 & 3 & 2.4 \\
\hline \multirow{2}{*}{$2016 / 2128$} & Gem & 286 & 234.5 & 3.0 & 2.9 \\
\hline & Stdev & 17 & 49.8 & 0.5 & 1.4 \\
\hline Analysenr. & $\begin{array}{l}\text { Visnr. } \\
\text { (heel) }\end{array}$ & $\begin{array}{l}\text { Lengte } \\
(\mathrm{mm}) \\
\end{array}$ & $\begin{array}{c}\text { Dicht } \\
\text { gewicht } \\
(\mathrm{g})\end{array}$ & $\begin{array}{c}\text { Leeftijd } \\
\text { (jaar) }\end{array}$ & $\begin{array}{l}\text { Lever- } \\
\text { gewicht } \\
(\mathrm{g})\end{array}$ \\
\hline \multirow[t]{10}{*}{ Heel } & 61 & 305 & 264 & 4 & 2.8 \\
\hline & 62 & 246 & 145 & 3 & 1.6 \\
\hline & 63 & 282 & 213 & 4 & 1.3 \\
\hline & 64 & 224 & 104 & 2 & 0.5 \\
\hline & 65 & 256 & 169 & 3 & 1.4 \\
\hline & 66 & 265 & 195 & 3 & 2.5 \\
\hline & 67 & 245 & 136 & 2 & 0.8 \\
\hline & 68 & 280 & 189 & 3 & 1.8 \\
\hline & 69 & 305 & 260 & 3 & 2.3 \\
\hline & 70 & 242 & 129 & 3 & 0.9 \\
\hline \multirow[t]{2}{*}{$2016 / 2129$} & Gem & 265 & 180.3 & 3.0 & 1.6 \\
\hline & Stdev & 27 & 54.3 & 0.7 & 0.8 \\
\hline Analysenr. & $\begin{array}{l}\text { Visnr. } \\
\text { (heel) }\end{array}$ & $\begin{array}{l}\text { Lengte } \\
(\mathrm{mm})\end{array}$ & $\begin{array}{l}\text { Dicht } \\
\text { gewicht } \\
\text { (g) }\end{array}$ & $\begin{array}{c}\text { Leeftijd } \\
\text { (jaar) }\end{array}$ & $\begin{array}{l}\text { Lever- } \\
\text { gewicht } \\
\text { (g) }\end{array}$ \\
\hline \multirow[t]{10}{*}{ Heel } & 71 & 278 & 213 & 3 & 3.1 \\
\hline & 72 & 230 & 110 & 2 & 0.8 \\
\hline & 73 & 257 & 161 & 3 & 0.8 \\
\hline & 74 & 234 & 151 & 3 & 0.4 \\
\hline & 75 & 232 & 125 & 1 & 1.0 \\
\hline & 76 & 264 & 168 & 3 & 1.2 \\
\hline & 77 & 253 & 129 & 3 & 1.9 \\
\hline & 78 & 289 & 235 & 3 & 2.9 \\
\hline & 79 & 255 & 153 & 4 & 1.2 \\
\hline & 80 & 275 & 194 & 3 & 1.4 \\
\hline \multirow[t]{2}{*}{$2016 / 2130$} & Gem & 257 & 163.9 & 2.8 & 1.5 \\
\hline & Stdev & 20 & 39.8 & 0.8 & 0.9 \\
\hline
\end{tabular}

Analyse nrs

spoorelementen

\begin{tabular}{|l|c|c|c|c|c|}
\hline \multicolumn{1}{c|}{} & 1 & 2 & 3 & 4 & 5 \\
\hline Heel & $2016 / 2123$ & $2016 / 2124$ & $2016 / 2125$ & $2016 / 2126$ & $2016 / 2127$ \\
\hline
\end{tabular} \begin{tabular}{|l|l|l|l|l|l|}
\hline Filet & $2016 / 2133$ & $2016 / 2134$ & $2016 / 2135$ & $2016 / 2136$ & $2016 / 2137$ \\
\hline
\end{tabular} \begin{tabular}{|l|l|l|l|l|l|}
\hline Lever & $2016 / 2138$ & $2016 / 2139$ & $2016 / 2140$ & $2016 / 2141$ & $2016 / 2142$ \\
\hline
\end{tabular}

\begin{tabular}{|c|c|c|c|c|c|}
\hline Analysenr. & $\begin{array}{l}\text { Visnr. } \\
\text { (heel) }\end{array}$ & $\begin{array}{l}\text { Lengte } \\
(\mathrm{mm})\end{array}$ & $\begin{array}{l}\text { Dicht } \\
\text { gewicht } \\
\text { (g) }\end{array}$ & $\begin{array}{c}\text { Leeftijd } \\
\text { (jaar) }\end{array}$ & $\begin{array}{l}\text { Lever- } \\
\text { gewicht } \\
\text { (g) }\end{array}$ \\
\hline \multirow[t]{10}{*}{ Heel } & 1 & 283 & 198 & 3 & 1.7 \\
\hline & 2 & 272 & 204 & 3 & 1.2 \\
\hline & 3 & 297 & 263 & 3 & 3.1 \\
\hline & 4 & 287 & 237 & 3 & 1.9 \\
\hline & 5 & 298 & 251 & 4 & 3.7 \\
\hline & 6 & 271 & 192 & 2 & 1.6 \\
\hline & 7 & 222 & 101 & 2 & 0.5 \\
\hline & 8 & 287 & 255 & 3 & 3.1 \\
\hline & 9 & 235 & 125 & 2 & 0.6 \\
\hline & 10 & 279 & 192 & 3 & 0.7 \\
\hline \multirow[t]{2}{*}{$2016 / 2123$} & Gem & 273 & 201.8 & 2.8 & 1.8 \\
\hline & Stdev & 25 & 54.3 & 0.6 & 1.1 \\
\hline Analysenr. & $\begin{array}{l}\text { Visnr. } \\
\text { (heel) }\end{array}$ & $\begin{array}{l}\text { Lengte } \\
(\mathrm{mm})\end{array}$ & $\begin{array}{c}\text { Dicht } \\
\text { gewicht } \\
\text { (g) }\end{array}$ & $\begin{array}{c}\text { Leeftijd } \\
\text { (jaar) }\end{array}$ & $\begin{array}{l}\text { Lever- } \\
\text { gewicht } \\
\text { (g) }\end{array}$ \\
\hline \multirow[t]{10}{*}{ Heel } & 11 & 286 & 199 & 4 & 1.1 \\
\hline & 12 & 259 & 170 & 2 & 1.7 \\
\hline & 13 & 285 & 214 & 5 & 1.0 \\
\hline & 14 & 289 & 214 & 3 & 1.5 \\
\hline & 15 & 294 & 272 & 3 & 4.0 \\
\hline & 16 & 297 & 279 & 3 & 3.6 \\
\hline & 17 & 304 & 264 & 4 & 3.9 \\
\hline & 18 & 304 & 291 & 3 & 4.4 \\
\hline & 19 & 283 & 212 & 4 & 1.7 \\
\hline & 20 & 305 & 262 & 4 & 2.7 \\
\hline \multirow[t]{2}{*}{$2016 / 2124$} & Gem & 291 & 237.4 & 3.5 & 2.6 \\
\hline & Stdev & 14 & 40.7 & 0.8 & 1.3 \\
\hline
\end{tabular}

\begin{tabular}{|c|c|c|c|c|c|}
\hline Analysenr. & Visnr. & Lengte & $\begin{array}{c}\text { Dicht } \\
\text { gewicht } \\
(\text { heel })\end{array}$ & $\begin{array}{c}\text { Leeftijd } \\
\text { (jaar) }\end{array}$ & $\begin{array}{c}\text { Lever- } \\
\text { gewicht } \\
(\mathrm{gm})\end{array}$ \\
\hline \multirow{4}{*}{ Heel } & 21 & 303 & 286 & 3 & 5.9 \\
\cline { 2 - 6 } & 22 & 299 & 269 & 3 & 2.7 \\
\cline { 2 - 6 } & 23 & 287 & 239 & 3 & 2.7 \\
\cline { 2 - 6 } & 24 & 257 & 166 & 4 & 2.1 \\
\cline { 2 - 6 } & 25 & 286 & 215 & 3 & 1.6 \\
\cline { 2 - 6 } & 26 & 275 & 189 & 3 & 1.6 \\
\cline { 2 - 6 } & 27 & 302 & 307 & 3 & 4.2 \\
\cline { 2 - 6 } & 28 & 286 & 267 & 4 & 3.7 \\
\cline { 2 - 6 } & 29 & 285 & 226 & 3 & 2.7 \\
\cline { 2 - 6 } & 30 & 306 & 272 & 3 & 4.0 \\
\cline { 2 - 6 } & Gem & 289 & 243.6 & 3.2 & 3.1 \\
\cline { 2 - 6 } & Stdev & 15 & 44.7 & 0.4 & 1.3 \\
\hline
\end{tabular}

\begin{tabular}{|c|c|c|c|c|c|}
\hline Analysenr. & Visnr. & Lengte & $\begin{array}{c}\text { Dicht } \\
\text { gewicht } \\
(\mathrm{g})\end{array}$ & $\begin{array}{c}\text { Leeftijd } \\
\text { (jaar) }\end{array}$ & $\begin{array}{c}\text { Lever- } \\
\text { gewicht } \\
(\mathrm{g})\end{array}$ \\
\hline \multirow{4}{*}{ Heel } & 81 & 276 & 200 & 3 & 2.6 \\
\cline { 2 - 6 } & 82 & 302 & 256 & 3 & 2.7 \\
\cline { 2 - 6 } & 83 & 278 & 222 & 3 & 5.5 \\
\cline { 2 - 6 } & 84 & 291 & 214 & 3 & 2.3 \\
\cline { 2 - 6 } & 85 & 290 & 248 & 3 & 3.7 \\
\cline { 2 - 6 } & 86 & 259 & 158 & 3 & 0.6 \\
\cline { 2 - 6 } & 87 & 261 & 168 & 3 & 0.6 \\
\cline { 2 - 6 } & 88 & 198 & 80 & 1 & 0.4 \\
\cline { 2 - 6 } & 89 & 251 & 130 & 3 & 0.7 \\
\cline { 2 - 6 } & 90 & 282 & 236 & 3 & 2.8 \\
\cline { 2 - 6 } & Gem & 269 & 191.1 & 2.8 & 2.2 \\
\cline { 2 - 6 } & Stdev & 30 & 56.5 & 0.6 & 1.7 \\
\hline
\end{tabular}

\begin{tabular}{|c|c|c|c|c|c|}
\hline Analysenr. & Visnr. & Lengte & $\begin{array}{c}\text { Dicht } \\
\text { gewicht } \\
(\text { heel })\end{array}$ & $\begin{array}{c}\text { Leeftijd } \\
\text { (jaar) }\end{array}$ & $\begin{array}{c}\text { Lever- } \\
\text { gewicht } \\
(\mathrm{g})\end{array}$ \\
\hline \multirow{4}{*}{ Heel } & 31 & 300 & 301 & 3 & 2.7 \\
\cline { 2 - 6 } & 32 & 252 & 155 & 2 & 1.5 \\
\cline { 2 - 6 } & 33 & 228 & 95 & 2 & 0.7 \\
\cline { 2 - 6 } & 34 & 306 & 273 & 4 & 3.2 \\
\cline { 2 - 6 } & 35 & 239 & 112 & 2 & 0.6 \\
\cline { 2 - 6 } & 36 & 239 & 108 & 2 & 0.5 \\
\cline { 2 - 6 } & 37 & 253 & 148 & 2 & 1.4 \\
\cline { 2 - 6 } & 38 & 297 & 285 & 6 & 3.4 \\
\cline { 2 - 6 } & 39 & 242 & 118 & 2 & 0.7 \\
\cline { 2 - 6 } & 40 & 209 & 95 & 1 & 0.6 \\
\cline { 2 - 6 } & Gem & 257 & 168.9 & 2.6 & 1.5 \\
\cline { 2 - 6 } & Stdev & 33 & 83.4 & 1.4 & 1.1 \\
\hline
\end{tabular}

\begin{tabular}{|c|c|c|c|c|c|}
\hline Analysenr. & Visnr. & Lengte & $\begin{array}{c}\text { Dicht } \\
\text { gewicht } \\
(\mathrm{g})\end{array}$ & $\begin{array}{c}\text { Leeftijd } \\
\text { (jaar) }\end{array}$ & $\begin{array}{c}\text { Lever- } \\
\text { gewicht } \\
(\mathrm{g})\end{array}$ \\
\hline \multirow{4}{*}{ Heel } & 91 & 223 & 106 & 2 & 0.9 \\
\cline { 2 - 6 } & 92 & 223 & 117 & 2 & 0.7 \\
\cline { 2 - 6 } & 93 & 257 & 160 & 3 & 1.3 \\
\cline { 2 - 6 } & 94 & 226 & 113 & 2 & 0.9 \\
\cline { 2 - 6 } & 95 & 252 & 144 & 3 & 1.3 \\
\cline { 2 - 6 } & 96 & 274 & 231 & 3 & 3.4 \\
\cline { 2 - 6 } & 97 & 280 & 222 & 3 & 2.4 \\
\cline { 2 - 6 } & 98 & 287 & 248 & 4 & 2.2 \\
\cline { 2 - 6 } & 99 & 260 & 183 & 2 & 1.5 \\
\cline { 2 - 6 } & 100 & 288 & 237 & 3 & 3.7 \\
\cline { 2 - 6 } & Gem & 257 & 176.1 & 2.7 & 1.8 \\
\cline { 2 - 6 } & Stdev & 26 & 55.5 & 0.7 & 1.1 \\
\hline
\end{tabular}

\begin{tabular}{|c|c|c|c|c|c|}
\hline Analysenr. & Visnr. & Lengte & $\begin{array}{c}\text { Dicht } \\
\text { gewicht } \\
(\mathrm{g})\end{array}$ & $\begin{array}{c}\text { Leeftijd } \\
\text { (jaar) }\end{array}$ & $\begin{array}{c}\text { Lever- } \\
\text { gewicht } \\
(\mathrm{g})\end{array}$ \\
\hline \multirow{4}{*}{ Heel } & 41 & 250 & 144 & 2 & 0.8 \\
\cline { 2 - 6 } & 42 & 301 & 311 & 4 & 5.0 \\
\cline { 2 - 6 } & 43 & 249 & 125 & 4 & 0.6 \\
\cline { 2 - 6 } & 44 & 270 & 208 & 2 & 2.3 \\
\cline { 2 - 6 } & 45 & 230 & 124 & 2 & 0.7 \\
\cline { 2 - 6 } & 46 & 257 & 155 & 3 & 1.7 \\
\cline { 2 - 6 } & 47 & 292 & 239 & 4 & 3.1 \\
\cline { 2 - 6 } & 48 & 230 & 124 & 3 & 0.7 \\
\cline { 2 - 6 } & 49 & 272 & 163 & 3 & 1.0 \\
\cline { 2 - 6 } & 50 & 296 & 225 & 3 & 3.4 \\
\cline { 2 - 6 } & Gem & 265 & 182.0 & 3.0 & 1.9 \\
\cline { 2 - 6 } & Stdev & 26 & 62.3 & 0.8 & 1.5 \\
\hline
\end{tabular}


JAMP Schol 2016 / Bijlage 4: Metaalgehalten schollever, kwikgehalten scholspierweefsel

Metaalgehalten in schollever in $\mathrm{mg} / \mathrm{kg}$ produkt, vet B\&D in $\mathrm{g} / \mathrm{kg}$ en droge stof in \%

Locatie West van IJmuiden (80 km): IJMWT80

\begin{tabular}{|c|c|c|c|c|c|c|}
\hline Analyse nr. & $\begin{array}{c}\text { Cadmium } \\
\text { Q }\end{array}$ & $\begin{array}{c}\text { Zink } \\
\text { Q }\end{array}$ & $\begin{array}{c}\text { Koper } \\
\text { Q }\end{array}$ & $\begin{array}{c}\text { Lood } \\
\text { Q }\end{array}$ & $\begin{array}{c}\text { Droge stof } \\
\text { Q }\end{array}$ & $\begin{array}{c}\text { Vet B\&D } \\
\text { Q }\end{array}$ \\
\hline $2016 / 2088$ & 0.069 & 31 & 3.9 & 0.046 & 18.0 & 31 \\
\hline $2016 / 2089$ & 0.077 & 37 & 4.6 & 0.046 & 22.9 & 68 \\
\hline $2016 / 2090$ & 0.078 & 40 & 3.7 & 0.034 & 21.8 & 55 \\
\hline $2016 / 2091$ & 0.074 & 36 & 4.5 & 0.047 & 18.0 & 37 \\
\hline $2016 / 2092$ & 0.059 & 35 & 2.9 & 0.041 & 14.1 & 17 \\
\hline
\end{tabular}

Locatie NW-Terschelling (40km): TERSLNWT40

\begin{tabular}{|c|c|c|c|c|c|c|}
\hline Analyse nr. & $\begin{array}{c}\text { Cadmium } \\
\text { Q }\end{array}$ & $\begin{array}{c}\text { Zink } \\
\text { Q }\end{array}$ & $\begin{array}{c}\text { Koper } \\
\text { Q }\end{array}$ & $\begin{array}{c}\text { Lood } \\
\text { Q }\end{array}$ & $\begin{array}{c}\text { Droge stof } \\
\text { Q }\end{array}$ & $\begin{array}{c}\text { Vet B\&D } \\
\text { Q }\end{array}$ \\
\hline $2016 / 2113$ & 0.074 & 42 & 4.8 & 2.1 & 22.0 & 80 \\
\hline $2016 / 2114$ & 0.061 & 31 & 3.2 & 1.1 & 22.1 & 72 \\
\hline $2016 / 2115$ & 0.053 & 31 & 2.3 & 1.2 & 21.8 & 62 \\
\hline $2016 / 2116$ & 0.068 & 30 & 2.1 & 2.1 & 17.7 & 33 \\
\hline $2016 / 2117$ & 0.074 & 38 & 4.6 & 2.1 & 21.1 & 59 \\
\hline
\end{tabular}

\begin{tabular}{|c|c|c|}
\hline Analyse nr. & $\begin{array}{c}\text { Kwik } \\
\text { Q }\end{array}$ & $\begin{array}{c}\text { Droge stof } \\
\text { Q }\end{array}$ \\
\hline $2016 / 2108$ & 0.054 & 17.8 \\
\hline $2016 / 2109$ & 0.041 & 19.1 \\
\hline $2016 / 2110$ & 0.035 & 18.5 \\
\hline $2016 / 2111$ & 0.043 & 18.5 \\
\hline $2016 / 2112$ & 0.051 & 18.9 \\
\hline
\end{tabular}

\section{Locatie Doggersbank: DOGGBK}

\begin{tabular}{|c|c|c|c|c|c|c|}
\hline Analyse nr. & $\begin{array}{c}\text { Cadmium } \\
\text { Q }\end{array}$ & $\begin{array}{c}\text { Zink } \\
\text { Q }\end{array}$ & $\begin{array}{c}\text { Koper } \\
\text { Q }\end{array}$ & $\begin{array}{c}\text { Lood } \\
\text { Q }\end{array}$ & $\begin{array}{c}\text { Droge stof } \\
\text { Q }\end{array}$ & $\begin{array}{c}\text { Vet B\&D } \\
\text { Q }\end{array}$ \\
\hline $2016 / 2138$ & 0.080 & 45 & 4.2 & 0.028 & 33.1 & 195 \\
\hline $2016 / 2139$ & 0.085 & 41 & 3.8 & 0.036 & 34.9 & 216 \\
\hline $2016 / 2140$ & 0.060 & 47 & 3.1 & 0.024 & 36.0 & 223 \\
\hline $2016 / 2141$ & 0.066 & 42 & 3.6 & 0.037 & 31.3 & 171 \\
\hline $2016 / 2142$ & 0.063 & 38 & 4.4 & 0.038 & 30.2 & 180 \\
\hline
\end{tabular}

\begin{tabular}{|c|c|c|}
\hline Analyse nr. & $\begin{array}{c}\text { Kwik } \\
\text { Q }\end{array}$ & $\begin{array}{c}\text { Droge stof } \\
\text { Q }\end{array}$ \\
\hline $2016 / 2133$ & 0.017 & 20.1 \\
\hline $2016 / 2134$ & 0.028 & 20.0 \\
\hline $2016 / 2135$ & 0.024 & 19.7 \\
\hline $2016 / 2136$ & 0.022 & 20.0 \\
\hline $2016 / 2137$ & 0.020 & 20.0 \\
\hline
\end{tabular}

Kwik gehalten in scholspierweefsel in $\mathrm{mg} / \mathrm{kg}$,

Droge stof in \%

\begin{tabular}{|c|c|c|}
\hline Analyse nr. & $\begin{array}{c}\text { Kwik } \\
\text { Q }\end{array}$ & $\begin{array}{c}\text { Droge stof } \\
\text { Q }\end{array}$ \\
\hline $2016 / 2083$ & 0.043 & 19.2 \\
\hline $2016 / 2084$ & 0.044 & 19.3 \\
\hline $2016 / 2085$ & 0.037 & 19.2 \\
\hline $2016 / 2086$ & 0.036 & 18.7 \\
\hline $2016 / 2087$ & 0.038 & 18.4 \\
\hline
\end{tabular}

Q ISO 17025 
JAMP Schol 2016 / Bijlage 5.1: PCB's en OCP's gehalten schol

PCB- en OCP-gehalten in schollever in $\mu \mathrm{g} / \mathrm{kg}$ produkt, vet in $\mathrm{g} / \mathrm{kg}$ en droge stof in \%

Locatie West van IJmuiden (80 km): IJMWT80

\begin{tabular}{|c|c|c|c|c|c|c|c|c|c|}
\hline Analysenr. & $\begin{array}{c}\text { CB-28 } \\
Q\end{array}$ & $\begin{array}{c}\text { CB-31 } \\
Q\end{array}$ & $\begin{array}{c}\text { CB-47 } \\
Q\end{array}$ & $\begin{array}{c}\text { CB-49 } \\
Q\end{array}$ & $\begin{array}{c}\text { CB-52 } \\
Q\end{array}$ & $\begin{array}{c}\text { CB-56 } \\
Q\end{array}$ & $\begin{array}{c}\text { CB-66 } \\
Q\end{array}$ & $\begin{array}{c}\text { CB-85 } \\
Q\end{array}$ & $\begin{array}{c}\text { CB-87 } \\
\text { Q }\end{array}$ \\
\hline $2016 / 2093$ & $<0.5$ & $<0.4$ & $\mathrm{nb}$ & $<0.5$ & $<0.6$ & $<0.7$ & $<0.6$ & 0.5 & 0.4 \\
\hline $2016 / 2094$ & $<1.0$ & $<0.4$ & $\mathrm{nb}$ & $<1.2$ & $<1.6$ & $<0.7$ & $<1.0$ & 0.6 & 0.6 \\
\hline $2016 / 2095$ & $<0.4$ & $<0.3$ & $\mathrm{nb}$ & $<0.3$ & $<0.4$ & $<0.6$ & $<0.4$ & $<0.3$ & 0.3 \\
\hline $2016 / 2096$ & $<0.5$ & $<0.2$ & $\mathrm{nb}$ & $<0.4$ & $<0.5$ & $<0.4$ & $<0.6$ & 0.4 & 0.3 \\
\hline $2016 / 2097$ & $<0.5$ & $<0.2$ & $\mathrm{nb}$ & $<0.4$ & $<0.5$ & $<0.4$ & $<0.4$ & 0.3 & 0.3 \\
\hline
\end{tabular}

\begin{tabular}{|c|c|c|c|c|c|c|c|c|c|}
\hline Analyse $\mathrm{nr}$. & $\begin{array}{c}\text { CB-97 } \\
\text { Q }\end{array}$ & $\begin{array}{c}\text { CB-101 } \\
Q\end{array}$ & $\begin{array}{c}\text { CB-105 } \\
Q\end{array}$ & $\begin{array}{c}\text { CB-110 } \\
Q\end{array}$ & $\begin{array}{c}\text { CB-118 } \\
Q\end{array}$ & $\begin{array}{c}\text { CB-128 } \\
\text { Q }\end{array}$ & $\begin{array}{c}\text { CB-137 } \\
\text { Q }\end{array}$ & $\begin{array}{c}\text { CB-138 } \\
Q\end{array}$ & $\begin{array}{c}\text { CB-141 } \\
\text { Q }\end{array}$ \\
\hline 2016/2093 & 0.5 & 0.9 & $<0.7$ & $<0.9$ & 2.7 & $<0.3$ & $<0.2$ & 3.3 & $<0.3$ \\
\hline 2016/2094 & 0.8 & 2.8 & $\mathrm{nb}$ & 2.1 & 3.7 & 0.6 & $<0.2$ & 5.2 & $<0.4$ \\
\hline 2016/2095 & 0.5 & 0.6 & $\mathrm{nb}$ & $<0.7$ & 2.6 & 0.4 & $<0.2$ & 3.3 & $<0.3$ \\
\hline $2016 / 2096$ & 0.4 & 1.0 & $\mathrm{nb}$ & $<0.8$ & 3.3 & 0.9 & $<0.1$ & 5.5 & $<0.2$ \\
\hline $2016 / 2097$ & 0.3 & 1.1 & $\mathrm{nb}$ & $<0.8$ & 2.2 & 0.4 & $<0.1$ & 3.5 & $<0.2$ \\
\hline
\end{tabular}

\begin{tabular}{|c|c|c|c|c|c|c|c|c|c|}
\hline Analyse $\mathrm{nr}$. & $\begin{array}{c}\text { CB-149 } \\
Q\end{array}$ & $\begin{array}{c}\text { CB-151 } \\
Q\end{array}$ & $\begin{array}{c}\text { CB-153 } \\
Q\end{array}$ & $\begin{array}{c}\text { CB-156 } \\
Q\end{array}$ & $\begin{array}{c}\text { CB-170 } \\
Q\end{array}$ & $\begin{array}{c}\text { CB-180 } \\
Q\end{array}$ & $\begin{array}{c}\text { CB-187 } \\
\text { Q }\end{array}$ & $\begin{array}{c}\text { CB-194 } \\
\text { Q }\end{array}$ & CB-202 \\
\hline $2016 / 2093$ & $<0.9$ & 0.8 & 6.0 & $<0.5$ & $<0.5$ & 1.4 & 1.8 & $<0.3$ & 0.3 \\
\hline $2016 / 2094$ & 2.5 & 1.5 & 9.1 & $<0.5$ & $<0.5$ & 2.4 & 3.1 & $<0.4$ & $<0.2$ \\
\hline $2016 / 2095$ & $<0.7$ & 0.7 & 5.6 & $<0.4$ & $<0.4$ & 1.3 & 1.8 & $<0.3$ & 0.3 \\
\hline $2016 / 2096$ & 0.7 & 0.8 & 10 & $<0.3$ & $<0.3$ & 2.5 & 2.1 & $<0.2$ & 0.5 \\
\hline $2016 / 2097$ & 0.9 & 0.9 & 6.8 & $<0.3$ & $<0.3$ & 1.8 & 2.5 & $<0.2$ & 0.2 \\
\hline
\end{tabular}

\begin{tabular}{|c|c|c|c|c|c|c|}
\hline Analyse nr. & $\begin{array}{c}\text { CB-206 } \\
\text { Q }\end{array}$ & $\begin{array}{c}\text { HCB } \\
\text { Q }\end{array}$ & $\begin{array}{c}\text { HCBD } \\
\text { Q }\end{array}$ & Heptachloor & $\begin{array}{c}\text { Droge stof } \\
\text { Q }\end{array}$ & $\begin{array}{c}\text { Vet(BD) } \\
\text { Q }\end{array}$ \\
\hline $2016 / 2093$ & $<0.3$ & $<0.3$ & $<0.2$ & $<0.4$ & 20.5 & 56 \\
\hline $2016 / 2094$ & $<0.4$ & $<0.7$ & $<0.2$ & $<0.4$ & 23.1 & 101 \\
\hline $2016 / 2095$ & $<0.3$ & $<0.4$ & $<0.2$ & $<0.3$ & 21.7 & 54 \\
\hline $2016 / 2096$ & $<0.2$ & $<0.7$ & $<0.1$ & $<0.2$ & 24.5 & 102 \\
\hline $2016 / 2097$ & $<0.2$ & $<0.4$ & $<0.1$ & $<0.2$ & 19.6 & 52 \\
\hline
\end{tabular}

Q ISO 17025

indicatief, kwaliteitswaardecode 4 
JAMP Schol 2016 / Bijlage 5.2: PCB's en OCP's gehalten schol

PCB- en OCP-gehalten in schollever in $\mu \mathrm{g} / \mathrm{kg}$ produkt, vet in $\mathrm{g} / \mathrm{kg}$ en droge stof in \%

Locatie NW-Terschelling (40km): TERSLNWT40

\begin{tabular}{|c|c|c|c|c|c|c|c|c|c|}
\hline Analysenr. & $\begin{array}{c}\text { CB-28 } \\
Q\end{array}$ & $\begin{array}{c}\text { CB-31 } \\
Q\end{array}$ & $\begin{array}{c}\text { CB-47 } \\
Q\end{array}$ & $\begin{array}{c}\text { CB-49 } \\
Q\end{array}$ & $\begin{array}{c}\text { CB-52 } \\
Q\end{array}$ & $\begin{array}{c}\text { CB-56 } \\
Q\end{array}$ & $\begin{array}{c}\text { CB-66 } \\
Q\end{array}$ & $\begin{array}{c}\text { CB-85 } \\
Q\end{array}$ & $\begin{array}{c}\text { CB-87 } \\
Q\end{array}$ \\
\hline $2016 / 2118$ & $<0.4$ & $<0.2$ & $\mathrm{nb}$ & $<0.3$ & $<0.3$ & $<0.4$ & $<0.3$ & 0.2 & 0.3 \\
\hline $2016 / 2119$ & $<0.3$ & $<0.2$ & $\mathrm{nb}$ & $<0.3$ & $<0.3$ & $<0.4$ & $<0.3$ & 0.2 & 0.2 \\
\hline $2016 / 2120$ & $<0.4$ & $<0.2$ & $\mathrm{nb}$ & $<0.3$ & $<0.4$ & $<0.3$ & $<0.3$ & 0.2 & 0.3 \\
\hline $2016 / 2121$ & $<0.4$ & $<0.2$ & $\mathrm{nb}$ & $<0.3$ & $<0.4$ & $<0.4$ & $<0.3$ & 0.2 & 0.3 \\
\hline $2016 / 2122$ & $<0.9$ & $<0.2$ & $\mathrm{nb}$ & $<0.6$ & 0.9 & $<0.4$ & $<0.6$ & $<0.2$ & $<0.2$ \\
\hline
\end{tabular}

\begin{tabular}{|c|c|c|c|c|c|c|c|c|c|}
\hline Analyse $\mathrm{nr}$. & $\begin{array}{c}\text { CB-97 } \\
Q\end{array}$ & $\begin{array}{c}\text { CB-101 } \\
Q\end{array}$ & $\begin{array}{c}\text { CB-105 } \\
Q\end{array}$ & $\begin{array}{c}\text { CB-110 } \\
Q\end{array}$ & $\begin{array}{c}\text { CB-118 } \\
Q\end{array}$ & $\begin{array}{c}\text { CB-128 } \\
Q\end{array}$ & $\begin{array}{c}\text { CB-137 } \\
Q\end{array}$ & $\begin{array}{c}\text { CB-138 } \\
Q\end{array}$ & $\begin{array}{c}\text { CB-141 } \\
Q\end{array}$ \\
\hline $2016 / 2118$ & 0.3 & 0.7 & $\mathrm{nb}$ & $<0.6$ & 1.4 & $<0.2$ & $<0.1$ & 1.9 & $<0.2$ \\
\hline $2016 / 2119$ & 0.2 & 0.4 & $\mathrm{nb}$ & $<0.4$ & 1.1 & $<0.2$ & $<0.1$ & 1.5 & $<0.2$ \\
\hline $2016 / 2120$ & 0.3 & 0.6 & $\mathrm{nb}$ & $<0.5$ & 1.2 & $<0.2$ & $<0.1$ & 1.8 & $<0.2$ \\
\hline $2016 / 2121$ & 0.3 & 0.6 & $\mathrm{nb}$ & $<0.5$ & 1.2 & $<0.2$ & $<0.1$ & 1.7 & $<0.2$ \\
\hline $2016 / 2122$ & $<0.2$ & 1.3 & $\mathrm{nb}$ & $<0.3$ & 2.9 & $<0.2$ & $<0.1$ & 4.0 & $<0.2$ \\
\hline
\end{tabular}

\begin{tabular}{|c|c|c|c|c|c|c|c|c|c|}
\hline Analyse nr. & $\begin{array}{c}\text { CB-149 } \\
\text { Q }\end{array}$ & $\begin{array}{c}\text { CB-151 } \\
\text { Q }\end{array}$ & $\begin{array}{c}\text { CB-153 } \\
\text { Q }\end{array}$ & $\begin{array}{c}\text { CB-156 } \\
\text { Q }\end{array}$ & $\begin{array}{c}\text { CB-170 } \\
\text { Q }\end{array}$ & $\begin{array}{c}\text { CB-180 } \\
\text { Q }\end{array}$ & $\begin{array}{c}\text { CB-187 } \\
\text { Q }\end{array}$ & $\begin{array}{c}\text { CB-194 } \\
\text { Q }\end{array}$ & $\begin{array}{c}\text { CB-202 } \\
\end{array}$ \\
\hline $2016 / 2118$ & 0.6 & 0.5 & 3.1 & $<0.2$ & $<0.2$ & 0.6 & 1.1 & $<0.2$ & 0.4 \\
\hline $2016 / 2119$ & $<0.4$ & 0.4 & 2.4 & $<0.2$ & $<0.2$ & 0.5 & 0.6 & $<0.2$ & 0.3 \\
\hline $2016 / 2120$ & 0.6 & 0.4 & 2.9 & $<0.2$ & $<0.2$ & 0.6 & 1.0 & $<0.2$ & 0.3 \\
\hline $2016 / 2121$ & 0.5 & 0.4 & 2.6 & $<0.2$ & 0.2 & 0.5 & 0.9 & $<0.2$ & 0.4 \\
\hline $2016 / 2122$ & 1.3 & 0.8 & 7.8 & $<0.2$ & 0.7 & 1.8 & 0.6 & $<0.2$ & $<0.1$ \\
\hline
\end{tabular}

\begin{tabular}{|c|c|c|c|c|c|c|}
\hline Analyse $\mathrm{nr}$. & $\begin{array}{c}\text { CB-206 } \\
\mathrm{Q}\end{array}$ & $\begin{array}{c}\text { HCB } \\
\mathrm{Q}\end{array}$ & $\begin{array}{c}\text { HCBD } \\
\mathrm{Q}\end{array}$ & $\begin{array}{c}\text { Heptachloor } \\
\mathrm{Q}\end{array}$ & $\begin{array}{c}\text { Droge stof } \\
\mathrm{Q}\end{array}$ & $\begin{array}{c}\text { Vet(BD) } \\
\mathrm{Q}\end{array}$ \\
\hline $2016 / 2118$ & $<0.2$ & $<0.3$ & $<0.1$ & $<0.2$ & 22.2 & 54 \\
\hline $2016 / 2119$ & $<0.2$ & $<0.2$ & $<0.1$ & $<0.2$ & 21.0 & 51 \\
\hline $2016 / 2120$ & $<0.2$ & $<0.3$ & $<0.1$ & $<0.2$ & 21.5 & 53 \\
\hline $2016 / 2121$ & $<0.2$ & $<0.3$ & $<0.1$ & $<0.2$ & 22.1 & 51 \\
\hline $2016 / 2122$ & $<0.2$ & $\mathrm{nb}$ & 0.2 & $<0.2$ & 25.2 & 96 \\
\hline
\end{tabular}

Q ISO 17025

$\mathrm{nb}=$ niet bepaald, kwaliteitswaarde code 99

indicatief, kwaliteitswaardecode 4 
JAMP Schol 2016 / Bijlage 5.3: PCB's en OCP's gehalten schol

PCB- en OCP-gehalten in schollever in $\mu \mathrm{g} / \mathrm{kg}$ produkt, vet in $\mathrm{g} / \mathrm{kg}$ en droge stof in \%

Locatie Doggersbank: DOGGBK

\begin{tabular}{|c|c|c|c|c|c|c|c|c|c|}
\hline Analysenr. & $\begin{array}{c}\text { CB-28 } \\
Q\end{array}$ & $\begin{array}{c}\text { CB-31 } \\
Q\end{array}$ & $\begin{array}{c}\text { CB-47 } \\
Q\end{array}$ & $\begin{array}{c}\text { CB-49 } \\
Q\end{array}$ & $\begin{array}{c}\text { CB-52 } \\
Q\end{array}$ & $\begin{array}{c}\text { CB-56 } \\
Q\end{array}$ & $\begin{array}{c}\text { CB-66 } \\
Q\end{array}$ & $\begin{array}{c}\text { CB-85 } \\
Q\end{array}$ & $\begin{array}{c}\text { CB-87 } \\
Q\end{array}$ \\
\hline $2016 / 2143$ & $<0.6$ & $<0.2$ & $\mathrm{nb}$ & $<0.5$ & 0.9 & $<0.4$ & $<0.6$ & 0.3 & 0.5 \\
\hline $2016 / 2144$ & $<0.5$ & $<0.2$ & $\mathrm{nb}$ & $<0.4$ & $<0.6$ & $<0.4$ & $<0.5$ & 0.3 & 0.4 \\
\hline $2016 / 2145$ & $<0.5$ & $<0.2$ & $\mathrm{nb}$ & $<0.4$ & $<0.7$ & $<0.3$ & $<0.5$ & 0.3 & 0.4 \\
\hline $2016 / 2146$ & $<0.5$ & $<0.2$ & $\mathrm{nb}$ & $<0.4$ & $<0.6$ & $<0.4$ & $<0.4$ & 0.3 & 0.4 \\
\hline $2016 / 2147$ & $<0.6$ & $<0.2$ & $\mathrm{nb}$ & $<0.4$ & $<0.6$ & $<0.4$ & $<0.5$ & 0.3 & 0.4 \\
\hline
\end{tabular}

\begin{tabular}{|c|c|c|c|c|c|c|c|c|c|}
\hline Analyse $\mathrm{nr}$. & $\begin{array}{c}\text { CB-97 } \\
Q\end{array}$ & $\begin{array}{c}\text { CB-101 } \\
Q\end{array}$ & $\begin{array}{c}\text { CB-105 } \\
Q\end{array}$ & $\begin{array}{c}\text { CB-110 } \\
Q\end{array}$ & $\begin{array}{c}\text { CB-118 } \\
Q\end{array}$ & $\begin{array}{c}\text { CB-128 } \\
Q\end{array}$ & $\begin{array}{c}\text { CB-137 } \\
Q\end{array}$ & $\begin{array}{c}\text { CB-138 } \\
Q\end{array}$ & $\begin{array}{c}\text { CB-141 } \\
Q\end{array}$ \\
\hline $2016 / 2143$ & 0.5 & 1.6 & $\mathrm{nb}$ & 1.0 & 2.2 & 0.4 & $<0.1$ & 3.7 & $<0.2$ \\
\hline $2016 / 2144$ & 0.3 & 1.0 & $\mathrm{nb}$ & $<0.6$ & 1.8 & 0.3 & $<0.1$ & 2.8 & $<0.2$ \\
\hline $2016 / 2145$ & 0.4 & 1.1 & $\mathrm{nb}$ & $<0.6$ & 2.1 & 0.5 & $<0.1$ & 3.9 & $<0.2$ \\
\hline $2016 / 2146$ & 0.3 & 0.9 & $\mathrm{nb}$ & $<0.6$ & 1.5 & 0.3 & $<0.1$ & 2.6 & $<0.2$ \\
\hline $2016 / 2147$ & 0.4 & 1.0 & $\mathrm{nb}$ & $<0.6$ & 1.8 & 0.3 & $<0.1$ & 2.6 & $<0.2$ \\
\hline
\end{tabular}

\begin{tabular}{|c|c|c|c|c|c|c|c|c|c|}
\hline Analyse nr. & $\begin{array}{c}\text { CB-149 } \\
\text { Q }\end{array}$ & $\begin{array}{c}\text { CB-151 } \\
\text { Q }\end{array}$ & $\begin{array}{c}\text { CB-153 } \\
\text { Q }\end{array}$ & $\begin{array}{c}\text { CB-156 } \\
\text { Q }\end{array}$ & $\begin{array}{c}\text { CB-170 } \\
\text { Q }\end{array}$ & $\begin{array}{c}\text { CB-180 } \\
\text { Q }\end{array}$ & $\begin{array}{c}\text { CB-187 } \\
\text { Q }\end{array}$ & $\begin{array}{c}\text { CB-194 } \\
\text { Q }\end{array}$ & $\begin{array}{c}\text { CB-202 } \\
\end{array}$ \\
\hline $2016 / 2143$ & 1.3 & 0.8 & 5.1 & $<0.2$ & 0.3 & 0.8 & 1.5 & $<0.2$ & $<0.1$ \\
\hline $2016 / 2144$ & 0.8 & 0.6 & 4.1 & $<0.2$ & $<0.2$ & 0.7 & 1.0 & $<0.2$ & $<0.1$ \\
\hline $2016 / 2145$ & 0.9 & 0.6 & 5.8 & $<0.2$ & $<0.2$ & 0.9 & 1.1 & $<0.2$ & 0.2 \\
\hline $2016 / 2146$ & 0.8 & 0.5 & 3.7 & $<0.2$ & 0.3 & 0.7 & 0.8 & $<0.2$ & $<0.1$ \\
\hline $2016 / 2147$ & 0.8 & 0.5 & 3.7 & $<0.2$ & 0.3 & 0.6 & 0.8 & $<0.2$ & $<0.1$ \\
\hline
\end{tabular}

\begin{tabular}{|c|c|c|c|c|c|c|}
\hline Analyse nr. & $\begin{array}{c}\text { CB-206 } \\
\mathrm{Q}\end{array}$ & $\begin{array}{c}\text { HCB } \\
\mathrm{Q}\end{array}$ & $\begin{array}{c}\text { HCBD } \\
\mathrm{Q}\end{array}$ & $\begin{array}{c}\text { Heptachloor } \\
\mathrm{Q}\end{array}$ & $\begin{array}{c}\text { Droge stof } \\
\mathrm{Q}\end{array}$ & $\begin{array}{c}\text { Vet(BD) } \\
\mathrm{Q}\end{array}$ \\
\hline $2016 / 2143$ & $<0.2$ & 2.8 & $<0.1$ & $<0.2$ & 39.2 & 283 \\
\hline $2016 / 2144$ & $<0.2$ & 1.8 & $<0.1$ & $<0.2$ & 32.9 & 183 \\
\hline $2016 / 2145$ & $<0.2$ & 2.1 & $<0.1$ & $<0.2$ & 34.7 & 226 \\
\hline $2016 / 2146$ & $<0.2$ & 1.7 & $<0.1$ & $<0.2$ & 32.3 & 179 \\
\hline $2016 / 2147$ & $<0.2$ & 1.7 & $<0.1$ & $<0.2$ & 32.5 & 178 \\
\hline
\end{tabular}

Q ISO 17025

$\mathrm{nb}=$ niet bepaald, kwaliteitswaarde code 99

indicatief, kwaliteitswaardecode 4 
JAMP Schol 2016 / Bijlage 6: PBDE gehalten

PBDE gehalten in schollever in $\mu \mathrm{g} / \mathrm{kg}$ produkt

Locatie West van IJmuiden (80 km): IJMWT80

\begin{tabular}{|c|c|c|c|c|c|c|c|c|c|c|}
\hline Analysenr. & $\begin{array}{c}\text { BDE28 } \\
\mathrm{Q}\end{array}$ & $\begin{array}{c}\text { BDE47 } \\
\mathrm{Q}\end{array}$ & $\begin{array}{c}\text { BDE66 } \\
\text { Q }\end{array}$ & $\begin{array}{c}\text { BDE85 } \\
\text { Q }\end{array}$ & $\begin{array}{c}\text { BDE99 } \\
\text { Q }\end{array}$ & $\begin{array}{c}\text { BDE100 } \\
\text { Q }\end{array}$ & $\begin{array}{c}\text { BDE153 } \\
\text { Q }\end{array}$ & $\begin{array}{c}\text { BDE154 + } \\
\text { BB153 } \\
\text { Q }\end{array}$ & BDE183 & $\begin{array}{c}\text { HBCD } \\
\mathrm{Q}\end{array}$ \\
\hline $2016 / 2093$ & $<0.01$ & 0.3 & $<0.01$ & $<0.02$ & 0.07 & 0.09 & 1.6 & 0.06 & $<0.01$ & $<0.07$ \\
\hline $2016 / 2094$ & $<0.01$ & 0.3 & $<0.01$ & $<0.02$ & 0.06 & 0.06 & 1.9 & 0.03 & $<0.02$ & $<0.08$ \\
\hline $2016 / 2095$ & $<0.01$ & 0.2 & $<0.01$ & $<0.02$ & 0.04 & 0.04 & 0.9 & 0.02 & $<0.02$ & $<0.08$ \\
\hline $2016 / 2096$ & $<0.01$ & 0.3 & $<0.01$ & $<0.02$ & 0.06 & 0.07 & 0.8 & 0.04 & $<0.01$ & $<0.07$ \\
\hline $2016 / 2097$ & $<0.01$ & 0.6 & $<0.01$ & $<0.02$ & 0.1 & 0.2 & 0.8 & 0.08 & $<0.02$ & $<0.09$ \\
\hline
\end{tabular}

Locatie NW-Terschelling (40km): TERSLNWT40

\begin{tabular}{|c|c|c|c|c|c|c|c|c|c|c|}
\hline Analysenr. & $\begin{array}{c}\text { BDE28 } \\
\text { Q }\end{array}$ & $\begin{array}{c}\text { BDE47 } \\
\text { Q }\end{array}$ & $\begin{array}{c}\text { BDE66 } \\
\text { Q }\end{array}$ & $\begin{array}{c}\text { BDE85 } \\
\text { Q }\end{array}$ & $\begin{array}{c}\text { BDE99 } \\
\text { Q }\end{array}$ & $\begin{array}{c}\text { BDE100 } \\
\text { Q }\end{array}$ & $\begin{array}{c}\text { BDE153 } \\
\text { Q }\end{array}$ & $\begin{array}{c}\text { BDE154 + } \\
\text { BB153 } \\
\text { Q }\end{array}$ & BDE183 & $\begin{array}{c}\mathrm{HBCD} \\
\mathrm{Q}\end{array}$ \\
\hline $2016 / 2118$ & $<0.01$ & 0.3 & $<0.01$ & $<0.02$ & 0.03 & 0.05 & 0.05 & 0.03 & $<0.02$ & $<0.08$ \\
\hline $2016 / 2119$ & $<0.01$ & 0.3 & $<0.02$ & $<0.02$ & 0.06 & 0.07 & 0.2 & 0.05 & $<0.02$ & $<0.09$ \\
\hline $2016 / 2120$ & $<0.01$ & 0.3 & $<0.01$ & $<0.02$ & 0.06 & 0.05 & 0.06 & 0.03 & $<0.01$ & $<0.07$ \\
\hline $2016 / 2121$ & $<0.007$ & 0.3 & $<0.008$ & $<0.01$ & 0.04 & 0.08 & 0.08 & 0.05 & $<0.009$ & $<0.05$ \\
\hline $2016 / 2122$ & $<0.007$ & 0.4 & $<0.009$ & $<0.01$ & 0.04 & 0.09 & 0.06 & 0.04 & $<0.01$ & $<0.05$ \\
\hline
\end{tabular}

\section{Locatie Doggersbank: DOGGBK}

\begin{tabular}{|c|c|c|c|c|c|c|c|c|c|c|}
\hline Analysenr. & $\begin{array}{c}\text { BDE28 } \\
\text { Q }\end{array}$ & $\begin{array}{c}\text { BDE47 } \\
\text { Q }\end{array}$ & $\begin{array}{c}\text { BDE66 } \\
\text { Q }\end{array}$ & $\begin{array}{c}\text { BDE85 } \\
\text { Q }\end{array}$ & $\begin{array}{c}\text { BDE99 } \\
\text { Q }\end{array}$ & $\begin{array}{c}\text { BDE100 } \\
\text { Q }\end{array}$ & $\begin{array}{c}\text { BDE153 } \\
\text { Q }\end{array}$ & $\begin{array}{c}\text { BDE154 + } \\
\text { BB153 } \\
\text { Q }\end{array}$ & BDE183 & $\begin{array}{c}\mathrm{HBCD} \\
\mathrm{Q}\end{array}$ \\
\hline $2016 / 2143$ & 0.06 & 1.1 & $<0.01$ & 0.1 & 0.2 & 0.5 & 3.9 & 0.2 & $<0.01$ & $<0.06$ \\
\hline $2016 / 2144$ & $<0.01$ & 0.6 & $<0.01$ & 0.07 & 0.08 & 0.2 & 1.8 & 0.1 & $<0.02$ & $<0.08$ \\
\hline $2016 / 2145$ & 0.02 & 0.6 & $<0.02$ & 0.06 & 0.1 & 0.2 & 1.5 & 0.1 & $<0.02$ & $<0.09$ \\
\hline $2016 / 2146$ & $<0.01$ & 0.6 & 0.02 & 0.07 & 0.1 & 0.2 & 1.8 & 0.1 & $<0.02$ & $<0.08$ \\
\hline $2016 / 2147$ & $<0.01$ & 0.6 & 0.1 & 0.06 & 0.08 & 0.2 & 1.6 & 0.09 & $<0.02$ & $<0.08$ \\
\hline
\end{tabular}

Q ISO 17025 


\section{JAMP Schol 2016 / Bijlage 7: Perfluor gehalten}

\section{Perfluor gehalten in schollever in $\mu \mathrm{g} / \mathrm{kg}$ produkt}

Locatie West van IJmuiden (80 km): IJMWT80

\begin{tabular}{|c|c|c|c|c|c|c|c|c|}
\hline Analyse nr & PFBA & PFBS & PFDcA & PFDoA & PFDS & PFHpS & PFHxS & $\begin{array}{c}\text { PFOS } \\
\text { Q }\end{array}$ \\
\hline $2016 / 2093$ & $<0.5$ & $<0.9$ & $<1.0$ & $<1.0$ & $<1.9$ & $<1.0$ & $<0.9$ & 7.5 \\
\hline $2016 / 2094$ & $<0.6$ & $<1.1$ & 1.4 & $<1.3$ & $<2.5$ & $<1.2$ & $<1.2$ & 8.6 \\
\hline $2016 / 2095$ & $\mathrm{nb}$ & $\mathrm{nb}$ & $\mathrm{nb}$ & $\mathrm{nb}$ & $\mathrm{nb}$ & $\mathrm{nb}$ & $\mathrm{nb}$ & $\mathrm{nb}$ \\
\hline $2016 / 2096$ & $<0.4$ & $<0.7$ & 1.0 & $<0.8$ & $<1.5$ & $<0.8$ & $<0.7$ & 18 \\
\hline $2016 / 2097$ & $<0.3$ & $<0.6$ & 0.7 & $<0.7$ & $<1.4$ & $<0.7$ & $<0.7$ & 11 \\
\hline
\end{tabular}

\begin{tabular}{|c|c|c|c|c|c|c|c|c|}
\hline Analyse nr & PFHpA & PFHxA & PFNA & $\begin{array}{c}\text { PFOA } \\
\mathrm{Q}\end{array}$ & PFPeA & PFTeA & PFTrA & PFUnA \\
\hline $2016 / 2093$ & $<1.0$ & $<1.0$ & $<1.0$ & $<1.0$ & $<2.0$ & $\mathrm{nb}$ & $\mathrm{nb}$ & $<1.0$ \\
\hline $2016 / 2094$ & $<1.3$ & $<1.3$ & 1.6 & $<1.3$ & $<2.5$ & $\mathrm{nb}$ & $\mathrm{nb}$ & 1.3 \\
\hline $2016 / 2095$ & $\mathrm{nb}$ & $\mathrm{nb}$ & $\mathrm{nb}$ & $\mathrm{nb}$ & $\mathrm{nb}$ & $\mathrm{nb}$ & $\mathrm{nb}$ & $\mathrm{nb}$ \\
\hline $2016 / 2096$ & $<0.8$ & $<0.8$ & 1.0 & $<0.8$ & $<1.6$ & $\mathrm{nb}$ & $\mathrm{nb}$ & $<0.8$ \\
\hline $2016 / 2097$ & $<0.7$ & $<0.7$ & $<0.7$ & $<0.7$ & $<1.4$ & $\mathrm{nb}$ & $\mathrm{nb}$ & $<0.7$ \\
\hline
\end{tabular}

Locatie NW-Terschelling (40km): TERSLNWT40

\begin{tabular}{|l|c|c|c|c|c|c|c|c|}
\hline Analyse nr & PFBA & PFBS & PFDcA & PFDoA & PFDS & PFHpS & PFHxS & $\begin{array}{c}\text { PFOS } \\
\text { Q }\end{array}$ \\
\hline $2016 / 2118$ & $<0.4$ & $<0.8$ & 1.1 & $<0.9$ & $<1.7$ & $<0.9$ & $<0.9$ & 4.2 \\
\hline $2016 / 2119$ & $<0.2$ & $<0.5$ & 0.6 & $<0.5$ & $<1.0$ & $<0.5$ & $<0.5$ & 5.6 \\
\hline $2016 / 2120$ & $<0.3$ & $<0.5$ & $<0.6$ & $<0.6$ & $<1.1$ & $<0.6$ & $<0.6$ & 1.4 \\
\hline $2016 / 2121$ & $<0.2$ & $<0.4$ & $<0.5$ & $<0.5$ & $<1.0$ & $<0.5$ & $<0.5$ & $<0.5$ \\
\hline $2016 / 2122$ & $<0.3$ & $<0.7$ & $<0.8$ & $<0.8$ & $<1.4$ & $<0.7$ & $<0.7$ & 2.5 \\
\hline
\end{tabular}

Locatie Doggersbank: DOGGBK

\begin{tabular}{|l|c|c|c|c|c|c|c|c|}
\hline Analyse nr & PFBA & PFBS & PFDcA & PFDoA & PFDS & PFHpS & PFHxS & $\begin{array}{c}\text { PFOS } \\
\text { Q }\end{array}$ \\
\hline $2016 / 2143$ & $<0.3$ & $<0.6$ & $<0.7$ & $<0.7$ & $<1.4$ & $<0.7$ & $<0.7$ & $<0.7$ \\
\hline $2016 / 2144$ & $<0.2$ & $<0.5$ & 0.5 & $<0.5$ & $<1.0$ & $<0.5$ & $<0.5$ & 2.3 \\
\hline $2016 / 2145$ & $<0.3$ & $<0.6$ & $<0.6$ & $<0.6$ & $<1.2$ & $<0.6$ & $<0.6$ & $<0.6$ \\
\hline $2016 / 2146$ & $<0.3$ & $<0.7$ & 0.8 & $<0.7$ & $<1.4$ & $<0.7$ & $<0.7$ & $<0.7$ \\
\hline $2016 / 2147$ & $<0.3$ & $<0.6$ & $<0.7$ & $<0.7$ & $<1.2$ & $<0.6$ & $<0.6$ & $<0.6$ \\
\hline
\end{tabular}

\begin{tabular}{|l|c|c|c|c|c|c|c|c|}
\hline Analyse nr & PFHpA & PFHxA & PFNA & $\begin{array}{c}\text { PFOA } \\
\text { Q }\end{array}$ & PFPeA & PFTeA & PFTrA & PFUnA \\
\hline $2016 / 2143$ & $<0.7$ & $<0.7$ & $<0.7$ & $<0.7$ & $<1.4$ & $\mathrm{nb}$ & $\mathrm{nb}$ & $<0.7$ \\
\hline $2016 / 2144$ & $<0.5$ & $<0.5$ & 0.7 & $<0.5$ & $<1.0$ & $\mathrm{nb}$ & $\mathrm{nb}$ & 0.5 \\
\hline $2016 / 2145$ & $<0.6$ & $<0.6$ & $<0.6$ & $<0.6$ & $<1.2$ & $\mathrm{nb}$ & $\mathrm{nb}$ & $<0.6$ \\
\hline $2016 / 2146$ & $<0.7$ & $<0.7$ & $<0.7$ & $<0.7$ & $<1.5$ & $\mathrm{nb}$ & $\mathrm{nb}$ & $<0.7$ \\
\hline $2016 / 2147$ & $<0.7$ & $<0.7$ & $<0.7$ & $<0.7$ & $<1.3$ & $\mathrm{nb}$ & $\mathrm{nb}$ & $<0.7$ \\
\hline
\end{tabular}

Q ISO 17025 


\section{JAMP Schol 2016 / bijlage 8.1: Validatiegegevens analysemethoden}

\section{Resultaten referentiematerialen}

\begin{tabular}{|c|c|c|c|c|c|c|c|c|c|}
\hline Component & Referentiemateriaal & $\begin{array}{l}\text { IMARES-waarde } \\
\text { in } 2016\end{array}$ & \begin{tabular}{|c|}
$\mathrm{n}$ \\
in 2016 \\
\end{tabular} & $\begin{array}{c}\text { IMARES-waarde } \\
\text { QC-kaart }\end{array}$ & $\begin{array}{c}\mathrm{n} \\
\text { totaal }\end{array}$ & $\mathrm{ng} / \mathrm{dg}$ & $\begin{array}{c}\text { gecertificeerde } \\
\text { waarde }\end{array}$ & eenheid & kwalificatie \\
\hline PBDE28 & IRM 2014/004 aal & $0.33 \pm 0.01$ & 3 & $0.29 \pm 0.03$ & 14 & $\mathrm{ng}$ & n.v.t. & $\mu \mathrm{g} / \mathrm{kg}$ & goed \\
\hline PBDE47 & IRM 2014/004 aal & $22.0 \pm 2.1$ & 3 & $21.9 \pm 1.8$ & 13 & $\mathrm{ng}$ & n.v.t. & $\mu \mathrm{g} / \mathrm{kg}$ & goed \\
\hline PBDE99 & IRM 2014/004 aal & $1.10 \pm 0.026$ & 3 & $1.10 \pm 0.07$ & 14 & $\mathrm{ng}$ & n.v.t. & $\mu \mathrm{g} / \mathrm{kg}$ & goed \\
\hline PBDE100 & IRM 2014/004 aal & $8.0 \pm 0.35$ & 3 & $8.6 \pm 0.86$ & 14 & $\mathrm{ng}$ & n.v.t. & $\mu \mathrm{g} / \mathrm{kg}$ & goed \\
\hline PBDE119 & IRM 2014/004 aal & $0.141 \pm 0.0045$ & 2 & $0.13 \pm 0.039$ & 10 & $\mathrm{ng}$ & n.v.t. & $\mu \mathrm{g} / \mathrm{kg}$ & goed \\
\hline PBDE153 & IRM 2014/004 aal & $1.04 \pm 0.037$ & 3 & $1.06 \pm 0.07$ & 14 & $\mathrm{ng}$ & n.v.t. & $\mu \mathrm{g} / \mathrm{kg}$ & goed \\
\hline PBDE154 & IRM 2014/004 aal & $1.02 \pm 0.04$ & 3 & $0.97 \pm 0.09$ & 12 & $\mathrm{ng}$ & n.v.t. & $\mu \mathrm{g} / \mathrm{kg}$ & goed \\
\hline $\mathrm{HBCD}$ & IRM 2014/004 aal & $26.1 \pm 0.7$ & 3 & $26.7 \pm 2.9$ & 12 & $\mathrm{ng}$ & n.v.t. & $\mu \mathrm{g} / \mathrm{kg}$ & goed \\
\hline PFBA & IRM snoekbaars filer $1 \mathrm{e}$ interlab & $46.7 \pm 2.2$ & 5 & $49.9 \pm 4.1$ & 34 & $\mathrm{ng}$ & n.v.t. & $\mu \mathrm{g} / \mathrm{kg}$ & goed \\
\hline PFBS & IRM snoekbaars filer 1e interlab & $18.2 \pm 1.2$ & 6 & $19.8 \pm 2.3$ & 44 & $\mathrm{ng}$ & n.v.t. & $\mu \mathrm{g} / \mathrm{kg}$ & goed \\
\hline PFDcA & IRM snoekbaars filer 1e interlab & $2.9 \pm 0.28$ & 7 & $2.4 \pm 0.27$ & 20 & $\mathrm{ng}$ & n.v.t. & $\mu \mathrm{g} / \mathrm{kg}$ & goed \\
\hline PFDoA & IRM snoekbaars filer $1 \mathrm{e}$ interlab & $40.9 \pm 3.7$ & 5 & $40.4 \pm 6.0$ & 32 & $\mathrm{ng}$ & n.v.t. & $\mu \mathrm{g} / \mathrm{kg}$ & goed \\
\hline PFHXS & IRM snoekbaars filer 1e interlab & $20.1 \pm 1.7$ & 6 & $22.3 \pm 2.3$ & 43 & $\mathrm{ng}$ & n.v.t. & $\mu \mathrm{g} / \mathrm{kg}$ & goed \\
\hline PFNA & IRM snoekbaars filer 1e interlab & $1.5 \pm 0.40$ & 5 & $1.3 \pm 0.56$ & 36 & $\mathrm{ng}$ & n.v.t. & $\mu \mathrm{g} / \mathrm{kg}$ & goed \\
\hline PFOA & IRM snoekbaars filer $1 \mathrm{e}$ interlab & $10.4 \pm 0.73$ & 6 & $9.7 \pm 0.87$ & 49 & $\mathrm{ng}$ & n.v.t. & $\mu \mathrm{g} / \mathrm{kg}$ & goed \\
\hline PFOS & IRM snoekbaars filer 1e interlab & $78.9 \pm 1.6$ & 6 & $78.4 \pm 4.28$ & 61 & $\mathrm{ng}$ & n.v.t. & $\mu \mathrm{g} / \mathrm{kg}$ & goed \\
\hline Kwik & IRM Schol 2004/2069 & $0.0575 \pm 0.0029$ & 6 & $0.0585 \pm 0.0030$ & 40 & $\mathrm{ng}$ & n.v.t. & $\mathrm{mg} / \mathrm{kg}$ & goed \\
\hline Kwik & Oyster Tissue NIST1566b & $0.0386 \pm 0.0011$ & 6 & $0.0377 \pm 0.0017$ & 57 & $\mathrm{dg}$ & $0.0371 \pm 0.0013$ & $\mathrm{mg} / \mathrm{kg}$ & goed \\
\hline Dry-weight & IRM 2005/0775 Haring/makreel & $70.08 \pm 0.18$ & 9 & $70.00 \pm 0.252$ & 245 & $\mathrm{ng}$ & n.v.t. & $\%$ & goed \\
\hline Ash-Weight & IRM 2002/0757 Mosselen & $1.57 \pm 0.02$ & 3 & $1.58 \pm 0.04$ & 83 & $\mathrm{ng}$ & n.v.t. & $\%$ & goed \\
\hline Total-Lipid & IRM 2005/0775 Haring/makreel & $11.49 \pm 0.12$ & 16 & $11.54 \pm 0.14$ & 183 & $\mathrm{ng}$ & n.v.t. & $\%$ & goed \\
\hline CB28 & IRM 2014/004 aal & $6.16 \pm 0.57$ & 10 & $6.01 \pm 0.63$ & 12 & $\mathrm{ng}$ & n.v.t. & $\mu \mathrm{g} / \mathrm{kg}$ & goed \\
\hline CB52 & IRM 2014/004 aal & $47.0 \pm 1.9$ & 10 & $47.0 \pm 1.9$ & 12 & $\mathrm{ng}$ & n.v.t. & $\mu \mathrm{g} / \mathrm{kg}$ & goed \\
\hline CB49 & IRM 2014/004 aal & $12.2 \pm 0.5$ & 9 & $12.1 \pm 0.5$ & 11 & $\mathrm{ng}$ & n.v.t. & $\mu \mathrm{g} / \mathrm{kg}$ & goed \\
\hline CB66 & IRM 2014/004 aal & $20.1 \pm 0.6$ & 9 & $20.1 \pm 0.5$ & 11 & $\mathrm{ng}$ & n.v.t. & $\mu \mathrm{g} / \mathrm{kg}$ & goed \\
\hline CB101 & IRM 2014/004 aal & $74.4 \pm 3.2$ & 10 & $75.2 \pm 3.4$ & 12 & $\mathrm{ng}$ & n.v.t. & $\mu \mathrm{g} / \mathrm{kg}$ & goed \\
\hline CB97 & IRM 2014/004 aal & $16.5 \pm 0.4$ & 9 & $16.6 \pm 0.5$ & 11 & $\mathrm{ng}$ & n.v.t. & $\mu \mathrm{g} / \mathrm{kg}$ & goed \\
\hline CB87 & IRM 2014/004 aal & $9.87 \pm 0.37$ & 9 & $9.96 \pm 0.39$ & 11 & $\mathrm{ng}$ & n.v.t. & $\mu \mathrm{g} / \mathrm{kg}$ & goed \\
\hline CB85 & IRM 2014/004 aal & $9.08 \pm 0.46$ & 9 & $9.09 \pm 0.42$ & 11 & $\mathrm{ng}$ & n.v.t. & $\mu \mathrm{g} / \mathrm{kg}$ & goed \\
\hline CB110 & IRM 2014/004 aal & $71.7 \pm 3.4$ & 9 & $71.8 \pm 3.1$ & 11 & $\mathrm{ng}$ & n.v.t. & $\mu \mathrm{g} / \mathrm{kg}$ & goed \\
\hline CB151 & IRM 2014/004 aal & $27.0 \pm 1.6$ & 9 & $27.4 \pm 1.7$ & 12 & $\mathrm{ng}$ & n.v.t. & $\mu \mathrm{g} / \mathrm{kg}$ & goed \\
\hline CB149 & IRM 2014/004 aal & $119 \pm 7$ & 10 & $119 \pm 6$ & 12 & $\mathrm{ng}$ & n.v.t. & $\mu \mathrm{g} / \mathrm{kg}$ & goed \\
\hline CB118 & IRM 2014/004 aal & $76.1 \pm 1.8$ & 9 & $76.7 \pm 2.1$ & 12 & $\mathrm{ng}$ & n.v.t. & $\mu \mathrm{g} / \mathrm{kg}$ & goed \\
\hline CB153 & IRM 2014/004 aal & $313 \pm 22$ & 10 & $317 \pm 21$ & 12 & $\mathrm{ng}$ & n.v.t. & $\mu \mathrm{g} / \mathrm{kg}$ & goed \\
\hline CB141 & IRM 2014/004 aal & $15.7 \pm 1.1$ & 9 & $15.8 \pm 1.1$ & 11 & $\mathrm{ng}$ & n.v.t. & $\mu \mathrm{g} / \mathrm{kg}$ & goed \\
\hline CB105 & IRM 2014/004 aal & $13.9 \pm 0.6$ & 10 & $14.0 \pm 0.7$ & 12 & $\mathrm{ng}$ & n.v.t. & $\mu \mathrm{g} / \mathrm{kg}$ & goed \\
\hline CB138 & IRM 2014/004 aal & $150.7 \pm 8.6$ & 10 & $152.1 \pm 8.5$ & 12 & $\mathrm{ng}$ & n.v.t. & $\mu \mathrm{g} / \mathrm{kg}$ & goed \\
\hline CB187 & IRM 2014/004 aal & $87.6 \pm 3.1$ & 8 & $89.0 \pm 4.1$ & 10 & $\mathrm{ng}$ & n.v.t. & $\mu \mathrm{g} / \mathrm{kg}$ & goed \\
\hline CB128 & IRM 2014/004 aal & $22.1 \pm 1.2$ & 8 & $22.2 \pm 1.1$ & 10 & $\mathrm{ng}$ & n.v.t. & $\mu \mathrm{g} / \mathrm{kg}$ & goed \\
\hline CB156 & IRM 2014/004 aal & $10.1 \pm 1.1$ & 11 & $10.2 \pm 1.0$ & 13 & $\mathrm{ng}$ & n.v.t. & $\mu \mathrm{g} / \mathrm{kg}$ & goed \\
\hline CB180 & IRM 2014/004 aal & $88.8 \pm 6.2$ & 10 & $88.5 \pm 5.7$ & 12 & $\mathrm{ng}$ & n.v.t. & $\mu \mathrm{g} / \mathrm{kg}$ & goed \\
\hline CB170 & IRM 2014/004 aal & $27.9 \pm 1.3$ & 9 & $28.0 \pm 1.2$ & 11 & $\mathrm{ng}$ & n.v.t. & $\mu \mathrm{g} / \mathrm{kg}$ & goed \\
\hline HCBD & IRM 2014/004 aal & $6.52 \pm 0.57$ & 11 & $6.61 \pm 0.56$ & 13 & $\mathrm{ng}$ & n.v.t. & $\mu \mathrm{g} / \mathrm{kg}$ & goed \\
\hline $\mathrm{HCB}$ & IRM 2014/004 aal & $15.6 \pm 1.7$ & 12 & $15.5 \pm 1.5$ & 15 & $\mathrm{ng}$ & n.v.t. & $\mu \mathrm{g} / \mathrm{kg}$ & goed \\
\hline
\end{tabular}




\section{JAMP Schol 2016 / bijlage 8.2: Validatiegegevens analysemethoden}

\section{Resultaten Ringonderzoek Quasimeme in biota}

labcode: Q127 IMARES

\begin{tabular}{|c|c|c|c|c|c|c|c|c|c|}
\hline Group & Round & Period & Matrix & Determinand & Unit & Z-score & Qualification & Comment & accreditatie \\
\hline BT10 & 2016.01 & jan 2016 & QPF004BT & PFOS & $\mu \mathrm{g} / \mathrm{kg}$ & -0.3 & Satisfactory & Quasimeme & ja \\
\hline BT1 & 2016.01 & april 2016 & QTM109BT & Dry-weight & $\%$ & -0.3 & Satisfactory & Quasimeme & ja \\
\hline BT1 & 2016.01 & april 2016 & QTM110BT & Dry-weight & $\%$ & 0 & Satisfactory & Quasimeme & ja \\
\hline BT1 & 2016.02 & nov 2016 & QTM112BT & Dry-weight & $\%$ & 0 & Satisfactory & Quasimeme & ja \\
\hline BT1 & 2016.02 & nov 2016 & QTM113BT & Dry-weight & $\%$ & -0.2 & Satisfactory & Quasimeme & ja \\
\hline BT1 & 2016.01 & april 2016 & QTM110BT & Ash-Weight & $\%$ & -0.3 & Satisfactory & Quasimeme & ja \\
\hline BT1 & 2016.01 & april 2016 & QTM110BT & Total-Lipid & $\%$ & -0.1 & Satisfactory & Quasimeme & ja \\
\hline BT1 & 2016.02 & nov 2016 & QTM112BT & Total-Lipid & $\%$ & 0 & Satisfactory & Quasimeme & ja \\
\hline BT9 & 2016.01 & april 2016 & QBC046BT & BDE100 & $\mu \mathrm{g} / \mathrm{kg}$ & 0.1 & Satisfactory & Quasimeme & ja \\
\hline BT9 & 2016.01 & april 2016 & QBC047BT & BDE100 & $\mu \mathrm{g} / \mathrm{kg}$ & -1.1 & Satisfactory & Quasimeme & ja \\
\hline BT9 & 2016.01 & april 2016 & QBC046BT & BDE153 & $\mu \mathrm{g} / \mathrm{kg}$ & 0 & Satisfactory & Quasimeme & ja \\
\hline BT9 & 2016.01 & april 2016 & QBC047BT & BDE153 & $\mu \mathrm{g} / \mathrm{kg}$ & 2 & Satisfactory & Quasimeme & ja \\
\hline BT9 & 2016.01 & april 2016 & QBC046BT & BDE154 & $\mu \mathrm{g} / \mathrm{kg}$ & -0.4 & Satisfactory & Quasimeme & ja \\
\hline BT9 & 2016.01 & april 2016 & QBC047BT & BDE154 & $\mu \mathrm{g} / \mathrm{kg}$ & -0.9 & Satisfactory & Quasimeme & ja \\
\hline BT9 & 2016.01 & april 2016 & QBC047BT & BDE183 & $\mu \mathrm{g} / \mathrm{kg}$ & -2 & Satisfactory & Quasimeme & nee \\
\hline BT9 & 2016.01 & april 2016 & QBC046BT & BDE28 & $\mu \mathrm{g} / \mathrm{kg}$ & 0 & Satisfactory & Quasimeme & ja \\
\hline BT9 & 2016.01 & april 2016 & QBC047BT & BDE28 & $\mu \mathrm{g} / \mathrm{kg}$ & -0.3 & Satisfactory & Quasimeme & ja \\
\hline BT9 & 2016.01 & april 2016 & QBC046BT & BDE47 & $\mu \mathrm{g} / \mathrm{kg}$ & -0.1 & Satisfactory & Quasimeme & ja \\
\hline BT9 & 2016.01 & april 2016 & QBC047BT & BDE47 & $\mu \mathrm{g} / \mathrm{kg}$ & -1 & Satisfactory & Quasimeme & ja \\
\hline BT9 & 2016.01 & april 2016 & QBC047BT & BDE66 & $\mu \mathrm{g} / \mathrm{kg}$ & -1.5 & Satisfactory & Quasimeme & ja \\
\hline BT9 & 2016.01 & april 2016 & QBC047BT & BDE85 & $\mu \mathrm{g} / \mathrm{kg}$ & -0.6 & Satisfactory & Quasimeme & ja \\
\hline BT9 & 2016.01 & april 2016 & QBC046BT & BDE99 & $\mu \mathrm{g} / \mathrm{kg}$ & 1.6 & Satisfactory & Quasimeme & ja \\
\hline BT9 & 2016.01 & april 2016 & QBC047BT & BDE99 & $\mu \mathrm{g} / \mathrm{kg}$ & -0.7 & Satisfactory & Quasimeme & ja \\
\hline BT1 & 2016.02 & nov 2016 & QTM112BT & Kwik & $\mu \mathrm{g} / \mathrm{kg}$ & 1.9 & Satisfactory & Quasimeme & ja \\
\hline BT1 & 2016.02 & nov 2016 & QTM113BT & Kwik & $\mu \mathrm{g} / \mathrm{kg}$ & 1.1 & Satisfactory & Quasimeme & ja \\
\hline BT2 & 2015.02 & nov 2015 & QOR124BT & CB31 & $\mu \mathrm{g} / \mathrm{kg}$ & 0.21 & Satisfactory & Quasimeme & ja \\
\hline BT2 & 2015.02 & nov 2015 & QOR124BT & CB28 & $\mu \mathrm{g} / \mathrm{kg}$ & 0.25 & Satisfactory & Quasimeme & ja \\
\hline BT2 & 2015.02 & nov 2015 & QOR124BT & CB52 & $\mu \mathrm{g} / \mathrm{kg}$ & 0.23 & Satisfactory & Quasimeme & ja \\
\hline BT2 & 2015.02 & nov 2015 & QOR125BT & CB52 & $\mu \mathrm{g} / \mathrm{kg}$ & 0.81 & Satisfactory & Quasimeme & ja \\
\hline BT2 & 2015.02 & nov 2015 & QOR124BT & CB101 & $\mu \mathrm{g} / \mathrm{kg}$ & -0.3 & Satisfactory & Quasimeme & ja \\
\hline BT2 & 2015.02 & nov 2015 & QOR125BT & CB101 & $\mu \mathrm{g} / \mathrm{kg}$ & -0.11 & Satisfactory & Quasimeme & ja \\
\hline BT2 & 2015.02 & nov 2015 & QOR124BT & CB118 & $\mu \mathrm{g} / \mathrm{kg}$ & -0.58 & Satisfactory & Quasimeme & ja \\
\hline BT2 & 2015.02 & nov 2015 & QOR125BT & CB118 & $\mu \mathrm{g} / \mathrm{kg}$ & -0.27 & Satisfactory & Quasimeme & ja \\
\hline BT2 & 2015.02 & nov 2015 & QOR124BT & CB153 & $\mu \mathrm{g} / \mathrm{kg}$ & -0.17 & Satisfactory & Quasimeme & ja \\
\hline BT2 & 2015.02 & nov 2015 & QOR125BT & CB153 & $\mu \mathrm{g} / \mathrm{kg}$ & 0.01 & Satisfactory & Quasimeme & ja \\
\hline BT2 & 2015.02 & nov 2015 & QOR124BT & CB105 & $\mu \mathrm{g} / \mathrm{kg}$ & -0.29 & Satisfactory & Quasimeme & ja \\
\hline BT2 & 2015.02 & nov 2015 & QOR125BT & CB105 & $\mu \mathrm{g} / \mathrm{kg}$ & 0.15 & Satisfactory & Quasimeme & ja \\
\hline BT2 & 2015.02 & nov 2015 & QOR124BT & CB138 & $\mu \mathrm{g} / \mathrm{kg}$ & -0.96 & Satisfactory & Quasimeme & ja \\
\hline BT2 & 2015.02 & nov 2015 & QOR125BT & CB138 & $\mu \mathrm{g} / \mathrm{kg}$ & -0.73 & Satisfactory & Quasimeme & ja \\
\hline BT2 & 2015.02 & nov 2015 & QOR124BT & CB156 & $\mu \mathrm{g} / \mathrm{kg}$ & -1.13 & Satisfactory & Quasimeme & ja \\
\hline BT2 & 2015.02 & nov 2015 & QOR125BT & CB156 & $\mu \mathrm{g} / \mathrm{kg}$ & -1.76 & Satisfactory & Quasimeme & ja \\
\hline BT2 & 2015.02 & nov 2015 & QOR124BT & CB180 & $\mu \mathrm{g} / \mathrm{kg}$ & -0.85 & Satisfactory & Quasimeme & ja \\
\hline BT2 & 2015.02 & nov 2015 & QOR125BT & CB180 & $\mu \mathrm{g} / \mathrm{kg}$ & -0.6 & Satisfactory & Quasimeme & ja \\
\hline BT2 & 2015.02 & nov 2015 & QOR125BT & HCB & $\mu \mathrm{g} / \mathrm{kg}$ & 0.48 & Satisfactory & Quasimeme & ja \\
\hline BT2 & 2015.02 & nov 2015 & QOR124BT & $\mathrm{HCB}$ & $\mu \mathrm{g} / \mathrm{kg}$ & 0.61 & Satisfactory & Quasimeme & ja \\
\hline
\end{tabular}




\section{JAMP Schol 2016 / bijlage 8.3: Validatiegegevens analysemethoden}

\section{Rapportagegrenzen en meetonzekerheid}

\begin{tabular}{|c|c|c|c|c|c|c|c|}
\hline Component & $\begin{array}{l}\text { rapportage- } \\
\text { grens }\end{array}$ & $\begin{array}{l}\text { detectie- } \\
\text { limiet }\end{array}$ & unit & $\mathrm{ng} / \mathrm{dg}$ & $\begin{array}{c}\text { VC } \\
\text { rel. standard uncertainty (\%) }\end{array}$ & $\mathrm{n}$ & dc \\
\hline PBDE28 & 0.01 & 0.005 & $\mu \mathrm{g} / \mathrm{kg}$ & $\mathrm{ng}$ & 19.3 & 11 & 0 \\
\hline PBDE47 & 0.01 & 0.005 & $\mu \mathrm{g} / \mathrm{kg}$ & $\mathrm{ng}$ & 11.8 & 22 & 0 \\
\hline PBDE66 & 0.01 & 0.005 & $\mu \mathrm{g} / \mathrm{kg}$ & $\mathrm{ng}$ & 20.0 & & 0 \\
\hline PBDE85 & 0.02 & 0.01 & $\mu \mathrm{g} / \mathrm{kg}$ & $\mathrm{ng}$ & 20.0 & & 0 \\
\hline PBDE99 & 0.01 & 0.005 & $\mu \mathrm{g} / \mathrm{kg}$ & $\mathrm{ng}$ & 17.2 & 10 & 0 \\
\hline PBDE100 & 0.02 & 0.01 & $\mu \mathrm{g} / \mathrm{kg}$ & $\mathrm{ng}$ & 17.9 & 18 & 0 \\
\hline PBDE153 & 0.01 & 0.005 & $\mu \mathrm{g} / \mathrm{kg}$ & $\mathrm{ng}$ & 20.0 & 9 & 0 \\
\hline PBDE154+BB153 & 0.009 & 0.00 & $\mu \mathrm{g} / \mathrm{kg}$ & $\mathrm{ng}$ & 28.4 & 12 & 0 \\
\hline PBDE183 & 0.010 & 0.01 & $\mu \mathrm{g} / \mathrm{kg}$ & $\mathrm{ng}$ & 20.0 & & 0 \\
\hline HBCD & 0.070 & 0.04 & $\mu \mathrm{g} / \mathrm{kg}$ & $\mathrm{ng}$ & 20.0 & & 0 \\
\hline PFBA & 0.3 & 0.15 & $\mu \mathrm{g} / \mathrm{kg}$ & $\mathrm{ng}$ & 25.0 & & 0 \\
\hline PFPeA & 1.2 & 0.60 & $\mu \mathrm{g} / \mathrm{kg}$ & $\mathrm{ng}$ & 25.0 & & 0 \\
\hline PFHXA & 0.6 & 0.30 & $\mu \mathrm{g} / \mathrm{kg}$ & $\mathrm{ng}$ & 25.0 & & 0 \\
\hline PFHpA & 0.6 & 0.30 & $\mu \mathrm{g} / \mathrm{kg}$ & $\mathrm{ng}$ & 25.0 & & 0 \\
\hline PFOA & 0.6 & 0.30 & $\mu \mathrm{g} / \mathrm{kg}$ & $\mathrm{ng}$ & $17.8^{*}$ & 8 & 0 \\
\hline PFNA & 0.6 & 0.30 & $\mu \mathrm{g} / \mathrm{kg}$ & $\mathrm{ng}$ & 25.0 & & 0 \\
\hline PFDcA & 0.6 & 0.30 & $\mu \mathrm{g} / \mathrm{kg}$ & $\mathrm{ng}$ & 25.0 & & 0 \\
\hline PFUnA & 0.6 & 0.30 & $\mu \mathrm{g} / \mathrm{kg}$ & $\mathrm{ng}$ & 25.0 & & 0 \\
\hline PFDoA & 0.6 & 0.30 & $\mu \mathrm{g} / \mathrm{kg}$ & $\mathrm{ng}$ & 25.0 & & 0 \\
\hline PFBS & 0.60 & 0.30 & $\mu \mathrm{g} / \mathrm{kg}$ & $\mathrm{ng}$ & 25.0 & & 0 \\
\hline PFHxS & 0.60 & 0.30 & $\mu \mathrm{g} / \mathrm{kg}$ & $\mathrm{ng}$ & 25.0 & & 0 \\
\hline PFHpS & 0.6 & 0.3 & $\mu \mathrm{g} / \mathrm{kg}$ & $\mathrm{ng}$ & 25.0 & & 0 \\
\hline PFOS & 0.6 & 0.3 & $\mu \mathrm{g} / \mathrm{kg}$ & $\mathrm{ng}$ & $10.5^{\star}$ & 8 & 0 \\
\hline PFDS & 1.2 & 0.6 & $\mu \mathrm{g} / \mathrm{kg}$ & $\mathrm{ng}$ & 25.0 & & 0 \\
\hline PCB31 & 0.40 & 0.20 & $\mu \mathrm{g} / \mathrm{kg}$ & $\mathrm{ng}$ & 12.0 & 8 & 0 \\
\hline PCB28 & 0.30 & 0.15 & $\mu \mathrm{g} / \mathrm{kg}$ & $\mathrm{ng}$ & 10.4 & 8 & 0 \\
\hline PCB52 & 0.30 & 0.15 & $\mu \mathrm{g} / \mathrm{kg}$ & $\mathrm{ng}$ & 9.3 & 8 & 0 \\
\hline PCB49 & 0.30 & 0.15 & $\mu \mathrm{g} / \mathrm{kg}$ & $\mathrm{ng}$ & 10.7 & 8 & 0 \\
\hline PCB47 & 0.30 & 0.15 & $\mu \mathrm{g} / \mathrm{kg}$ & $\mathrm{ng}$ & 13.6 & 8 & 0 \\
\hline PCB66 & 0.40 & 0.20 & $\mu \mathrm{g} / \mathrm{kg}$ & $\mathrm{ng}$ & 9.3 & 8 & 0 \\
\hline PCB101 & 0.70 & 0.35 & $\mu \mathrm{g} / \mathrm{kg}$ & $\mathrm{ng}$ & 6.3 & 8 & 0 \\
\hline PCB97 & 0.30 & 0.15 & $\mu \mathrm{g} / \mathrm{kg}$ & $\mathrm{ng}$ & 7.0 & 8 & 0 \\
\hline PCB87 & 0.30 & 0.15 & $\mu \mathrm{g} / \mathrm{kg}$ & $\mathrm{ng}$ & 16.8 & 8 & 0 \\
\hline PCB85 & 0.30 & 0.15 & $\mu \mathrm{g} / \mathrm{kg}$ & $\mathrm{ng}$ & 3.4 & 8 & 0 \\
\hline PCB110 & 0.60 & 0.30 & $\mu \mathrm{g} / \mathrm{kg}$ & $\mathrm{ng}$ & 5.4 & 8 & 0 \\
\hline PCB151 & 0.40 & 0.20 & $\mu \mathrm{g} / \mathrm{kg}$ & $\mathrm{ng}$ & 6.1 & 8 & 0 \\
\hline PCB149 & 0.80 & 0.40 & $\mu \mathrm{g} / \mathrm{kg}$ & $\mathrm{ng}$ & 8.3 & 8 & 0 \\
\hline PCB118 & 0.90 & 0.45 & $\mu \mathrm{g} / \mathrm{kg}$ & $\mathrm{ng}$ & 6.5 & 8 & 0 \\
\hline PCB153 & 0.70 & 0.35 & $\mu \mathrm{g} / \mathrm{kg}$ & $\mathrm{ng}$ & 12.5 & 8 & 0 \\
\hline PCB141 & 0.30 & 0.15 & $\mu \mathrm{g} / \mathrm{kg}$ & $\mathrm{ng}$ & 9.3 & 8 & 0 \\
\hline PCB105 & 0.30 & 0.15 & $\mu \mathrm{g} / \mathrm{kg}$ & $\mathrm{ng}$ & 7.2 & 8 & 0 \\
\hline PCB138 & 0.70 & 0.35 & $\mu \mathrm{g} / \mathrm{kg}$ & $\mathrm{ng}$ & 13.0 & 8 & 0 \\
\hline PCB187 & 0.50 & 0.25 & $\mu \mathrm{g} / \mathrm{kg}$ & $\mathrm{ng}$ & 8.9 & 8 & 0 \\
\hline PCB128 & 0.30 & 0.15 & $\mu \mathrm{g} / \mathrm{kg}$ & $\mathrm{ng}$ & 8.9 & 8 & 0 \\
\hline PCB156 & 0.50 & 0.25 & $\mu \mathrm{g} / \mathrm{kg}$ & $\mathrm{ng}$ & 7.6 & 8 & 0 \\
\hline PCB180 & 0.30 & 0.15 & $\mu \mathrm{g} / \mathrm{kg}$ & $\mathrm{ng}$ & 11.4 & 8 & 0 \\
\hline PCB170 & 0.50 & 0.25 & $\mu \mathrm{g} / \mathrm{kg}$ & $\mathrm{ng}$ & 12.8 & 8 & 0 \\
\hline PCB56 & 0.70 & 0.35 & $\mu \mathrm{g} / \mathrm{kg}$ & $\mathrm{ng}$ & 4.4 & 8 & 0 \\
\hline PCB137 & 0.20 & 0.10 & $\mu \mathrm{g} / \mathrm{kg}$ & $\mathrm{ng}$ & 8.4 & 8 & 0 \\
\hline PCB202 & 0.20 & 0.10 & $\mu \mathrm{g} / \mathrm{kg}$ & $\mathrm{ng}$ & 6.6 & 8 & 0 \\
\hline PCB194 & 0.30 & 0.15 & $\mu \mathrm{g} / \mathrm{kg}$ & $\mathrm{ng}$ & 11.7 & 8 & 0 \\
\hline PCB206 & 0.30 & 0.15 & $\mu \mathrm{g} / \mathrm{kg}$ & $\mathrm{ng}$ & 14.6 & 8 & 0 \\
\hline HCBD & 0.20 & 0.100 & $\mu \mathrm{g} / \mathrm{kg}$ & $\mathrm{ng}$ & 7.5 & 8 & 0 \\
\hline $\mathrm{HCB}$ & 0.20 & 0.100 & $\mu \mathrm{g} / \mathrm{kg}$ & $\mathrm{ng}$ & 10.6 & 8 & 0 \\
\hline Heptachloor & 0.30 & 0.15 & $\mu \mathrm{g} / \mathrm{kg}$ & $\mathrm{ng}$ & 8.9 & 8 & 0 \\
\hline Kwik & 0.0008 & 0.0004 & $\mathrm{mg} / \mathrm{kg}$ & $\mathrm{ng}$ & 16.8 & 16 & 0 \\
\hline Dry-weight & 0.00037 & 0.00019 & $\mathrm{mg}$ & $\mathrm{ng}$ & 3.5 & 50 & 0 \\
\hline Total-Lipid & 0.003 & 0.0015 & $\%$ & $\mathrm{ng}$ & 16.6 & 39 & 0 \\
\hline
\end{tabular}

\begin{tabular}{|c|c|c|c|c|c|}
\hline Component & $\begin{array}{l}\text { |rapportag } \\
\text { grens Triske }\end{array}$ & unit & $\mathrm{ng} / \mathrm{dg}$ & $\begin{array}{c}\text { meetonzekerheid (\%) } \\
\text { Triskelion }\end{array}$ & \\
\hline Cadmium & 0.0003 & $\mathrm{mg} / \mathrm{kg}$ & $\mathrm{ng}$ & $8.7 \%$ op niveau van $1.3 \mathrm{mg} / \mathrm{kg}$ & 0 \\
\hline Zink & 0.25 & $\mathrm{mg} / \mathrm{kg}$ & $\mathrm{ng}$ & $8.5 \%$ op niveau van $69 \mathrm{mg} / \mathrm{kg}$ & 0 \\
\hline Koper & 0.015 & $\mathrm{mg} / \mathrm{kg}$ & $\mathrm{ng}$ & 9.0\% op niveau van $4.4 \mathrm{mg} / \mathrm{kg}$ & 0 \\
\hline Lood & 0.007 & $\mathrm{mg} / \mathrm{kg}$ & $\mathrm{ng}$ & $10 \%$ op niveau van $1.4 \mathrm{mg} / \mathrm{kg}$ & 0 \\
\hline
\end{tabular}

op basis van juistheidsbepaling en monsterinhomogeniteit

verwaarloosbaar klein

$\mathrm{n}=$ aantal ringonderzoeken aan de hand waarvan een Z-score bepaald kon worden

De meetonzekerheid opgegeven door Triskelion is opgebouwd uit de variatie in de lab-reproduceerbaarheid en uit de scores in ringonderzoeken

*Meetonzekerheid gebaseerd op de RMS van juistheidbepaling en de inhomogeniteitsbijdrage van de praktijkmonsters

dc is de combined constant error in de eenheid van de concentratie van de component 
Wageningen Marine Research

T: +31(0)317480900

E: marine-research@wur.nl

www.wur.nl/marine-research

Visitors address

- Ankerpark 271781 AG Den Helder

- Korringaweg 7, 4401 NT Yerseke

- Haringkade 1, 1976 CP IJmuiden
Wageningen Marine Research is the Netherlands research institute established to provide the scientific support that is essential for developing policies and innovation in respect of the marine environment, fishery activities, aquaculture and the maritime sector.

Wageningen University \& Research is specialised in the domain of healthy food and living environment.

The Wageningen Marine Research vision:

'To explore the potential of marine nature to improve the quality of life.'

The Wageningen Marine Research mission

- To conduct research with the aim of acquiring knowledge and offering advice on the sustainable management and use of marine and coastal areas.

- Wageningen Marine Research is an independent, leading scientific research institute.

Wageningen Marine Research is part of the international knowledge organisation Wageningen UR (University \& Research centre). Within Wageningen UR, nine specialised research institutes of Stichting Wageningen Research (a Foundation) have joined forces with Wageningen University to help answer the most important questions in the domain of healthy food and living environment. 